\title{
The green box: an electronically versatile perylene diimide macrocyclic host for fullerenes
}

\author{
Timothy A. Barendt, ${ }^{\dagger}{ }^{\dagger}$ Stuart P. Cornes, ${ }^{\ddagger}$ Maria A. Lebedeva, ${ }^{\dagger, \ddagger}$ William K. Myers, ${ }^{\S}$ \\ Kyriakos Porfyrakis ${ }^{\ddagger}$ and Paul D. Beer ${ }^{\star \dagger}$ \\ ${ }^{\dagger}$ Chemistry Research Laboratory, Department of Chemistry, University of Oxford, Mansfield Road, \\ Oxford OX 1 3TA, United Kingdom \\ ${ }^{\S}$ Centre for Advanced ESR, Inorganic Chemistry Laboratory, Department of Chemistry, University of \\ Oxford, South Parks Road, Oxford OX1 3QR, United Kingdom \\ ${ }^{\ddagger}$ Department of Materials, University of Oxford, Parks Road, Oxford $\mathrm{OX}_{1}{ }_{3} \mathrm{PH}$, United Kingdom
}

\begin{abstract}
The powerful electron accepting ability of fullerenes makes them ubiquitous components in biomimetic donor-acceptor systems that model the intermolecular electron transfer processes of Nature's photosynthetic centre. Exploiting perylene diimides (PDIs) as components in cyclic host systems for the noncovalent recognition of fullerenes is unprecedented, in part because archetypal PDIs are also electron deficient, making dyad assembly formation electronically unfavourable. To address this, we report the strategic design and synthesis of a novel large, macrocyclic receptor comprised of two covalently strapped electron-rich bis-pyrrolidine PDI panels, nicknamed the "Green Box" due to its colour. Through the principle of electronic complementarity, the Green Box exhibits strong recognition of pristine fullerenes $\left(\mathrm{C}_{60 / 70}\right)$, with the non-covalent ground and excited state interactions that occur upon fullerene guest encapsulation characterised by a range of techniques including electronic absorption, fluorescence emission, NMR and time-resolved EPR spectroscopies, cyclic voltammetry and mass spectrometry. Whilst relatively low polarity solvents result in partial charge transfer in the host donor-guest acceptor complex, increasing the polarity of the solvent medium facilitates rare, thermally allowed full electron transfer from Green Box to fullerene in the ground state. Both species in the ensuing charge separated radical ion paired complex are spectroscopically characterised, with thermodynamic reversibility and significant kinetic stability also demonstrated. Importantly, the Green Box represents a seminal type of $\mathrm{C}_{60 / 70}$ host where electron-rich PDI motifs are utilised as recognition motifs for fullerenes, facilitating novel intermolecular, solvent tuneable ground state electronic communication with these guests. The ability to switch between extremes of the charge transfer energy continuum is without precedent in synthetic fullerene-based dyads.
\end{abstract}

\section{Introduction}

Beyond their aesthetic appeal, fullerenes possess intriguing electrochemical, photophysical and magnetic properties $^{1,2}$ with a wide variety of applications stemming from photovoltaics ${ }^{3-5}$ and superconductors ${ }^{6-8}$ to biological $^{9-11}$ and organic electronics. ${ }^{12-15}$ Within the latter, the renowned electron accepting ability ${ }^{16}$ and small reorganisation energy ${ }^{17}$ of rigid symmetric fullerenes has led to their combination with electron donors to generate elegant models of Nature's photosynthetic reaction centre, ${ }^{18}$ that capture, transform and store energy via electronic donor-acceptor interactions. ${ }^{1,19}$ Such dyads have been constructed from covalent ${ }^{12,20-22}$ and mechanical bonds, ${ }^{23-28}$ however, a non-covalent approach ${ }^{15,29-31}$ is particularly desirable because it follows biomimetic principles of design whilst also preserving the singular electronic properties of fully conjugated cages such as pristine $C_{60}$ and $C_{70}$ fullerenes. ${ }^{32}$ (add Fullerenes Book Chapter 6 to this ref) Therefore, in conjunction with supramolecular chemistry, a range of synthetic receptor $\mathrm{s}^{33^{-50}}$ have been developed with the large cavities of preorganized macrocyclic hosts often providing the optimum strategy in terms of affinity and selectivity for discrete (add JACS 201711008 to this ref) fullerenes in solution. ${ }^{52,53}$ Hosts containing electron rich, lipophilic cavities are also preferential, on the basis of electronic complementarity towards the electron deficient fullerene guest, enabling interactions to be visualized spectroscopically. ${ }^{52-54}$ When these criteria are 
satisfied intermolecular partial charge transfer in the ground state and/or full single electron transfer (SET) in the excited state can occur between donor and acceptor. ${ }^{34,36,42,44}$ However, thermally promoted SET in the ground state, an extreme of the charge transfer energy continuum, ${ }^{55-57}$ is, to the best of our knowledge, unprecedented in a rationally designed fullerene-based dyad system.

Perylene diimides (PDIs) represent a class of chemically, thermally and photophysically stable organic dye molecules. ${ }^{58-60}$ Their rich photo- and electro-chemistry provides a wide range of visible light absorptions, characteristic long lived excited states and the ability to undergo efficient energy and electron transfer reactions, making them ideal components in synthetic donor-acceptor assemblies. ${ }^{61-65}$ However, the covalent $^{66-80}$ or non-covalent ${ }^{37,81,82}$ linking of PDI derivatives with $\mathrm{C}_{60}$ fullerene has generated dyads in which negligible electron communication has been observed spectroscopically in the ground state ${ }^{37,66-73,76,77,81-83}$ whilst energy transfer was the predominant relaxation pathway for the excited state. ${ }^{67-69,71,73,76,80,82}$ This is

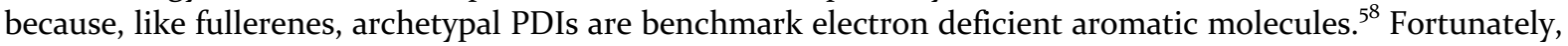
their electronic properties can be modulated such that the incorporation of electron-donating pyrrolidine heterocycles in two of the bay positions of the perylene core causes a large, negative shift in the oxidation potential to produce an electron-rich PDI. ${ }^{84}$ Furthermore, these chromophores are green with large extinction co-efficients in the highly desirable red and NIR regions, where a significant fraction of the solar spectrum occurs. ${ }^{85}$ Whilst two previously reported dyads comprised of a bis-pyrrolidine PDI and a covalently appended $C_{60}$ fullerene exhibit photoinduced electron transfer from donor to acceptor, ${ }^{79,83}$ spectroscopic evidence for strong electronic communication between these motifs in the ground state remains elusive, whilst host-guest non-covalent systems do not exist. Thermally promoted SET between a PDI motif and fullerene remains unknown.

Herein we describe the rational design, synthesis and fullerene recognition properties of a large, macrocyclic receptor comprised of two covalently strapped electron-rich bis-pyrrolidine PDI panels, nicknamed the "Green Box" due to its colour. These PDI chromophores were chosen because: (i) they provide electronic complementarity to electron-deficient fullerenes guests; (ii) the bis-bay substituted PDI aromatic framework is twisted and flexible ${ }^{85}$ to allow optimization of alignment/intimate contact with the convex surface of a fullerene ${ }^{86}$ and (iii) they are monomeric, exhibiting excellent solubility in organic solvents. Furthermore, aryl and alkyl spacer units were used in tandem to create a macrocyclic host with a preorganised, lipophilic cavity, whilst also maintaining some flexibility for structurally idealised guest encapsulation (size/shape complementarity). The novel ground and excited state electronic interactions between the macrocycle's PDI components and potential pristine $\mathrm{C}_{60 / 70}$ fullerene guest species were therefore pursued and demonstrated via a non-covalent approach. ${ }^{86}$ We have employed a range of techniques to comprehensively characterise the fullerene recognition properties of Green Box, 4, and its subsequent impact on the electronics of host and guest. For the first time, this work reveals a fullerene-based dyad with solvent tuneable partial charge $\left([4]^{\delta+} \subset\left[C_{60}\right]^{\delta-}\right)$ or full electron transfer $\left([4]^{++} \subset\left[C_{60}\right]^{--}\right)$in the ground state of the supramolecular complex assembly (Figure 1).

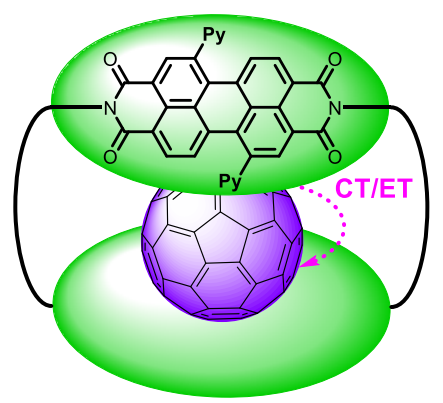

Figure 1. Schematic of pristine fullerene recognition inside the electron rich cavity of a bis-pyrrolidine PDI macrocycle (Green Box) and electronic communication in the host donor-guest acceptor complex. (CT = ground state partial charge transfer, ET = ground or excited state full electron transfer, Py = pyrrolidine).

\section{Synthesis and Characterisation}

The Green Box bis-PDI macrocycle 4 was prepared by a multi-step synthetic pathway as fully described in the Supporting Information (Scheme 1 and Supporting Information section 1). Initially, bis-pyrrolidine perylene3,4,9,10-tetracarboxylic dianhydride (PTCDA) ${ }^{87} \mathbf{1}$ was synthesised in four steps as the pure $\mathrm{C}_{1,7}$ bayfunctionalised regioisomer, whilst condensation with an appropriate amine ${ }^{88,89}$ afforded bis-pyrrolidine perylene-3,4,9,10-tetracarboxylic diimide (PDI) derivatives containing either butyl alkyne (2) or a biphenyl azide (3) at each of the imide termini. A [1+1] macrocyclization reaction was then performed with these 
precursors via a double copper(I)-catalyzed azide alkyne cycloaddition (CuAAC) "click" reaction under high dilution conditions $(0.5 \mathrm{mM})$ to give the large bis-perylene diimide-containing macrocycle $\mathbf{4}$ as a dark green solid (and in solution) in 40\% yield following purification by preparative silica thin-layer chromatography (Scheme 1, Figure $\mathbf{2 b}$ ). Compound $\mathbf{5}$ was also synthesised ${ }^{90}$ to act as a model for a single bis-pyrrolidine PDI panel and allow comparative studies to the Green Box (Scheme S1.1 and Supporting Information section 1).

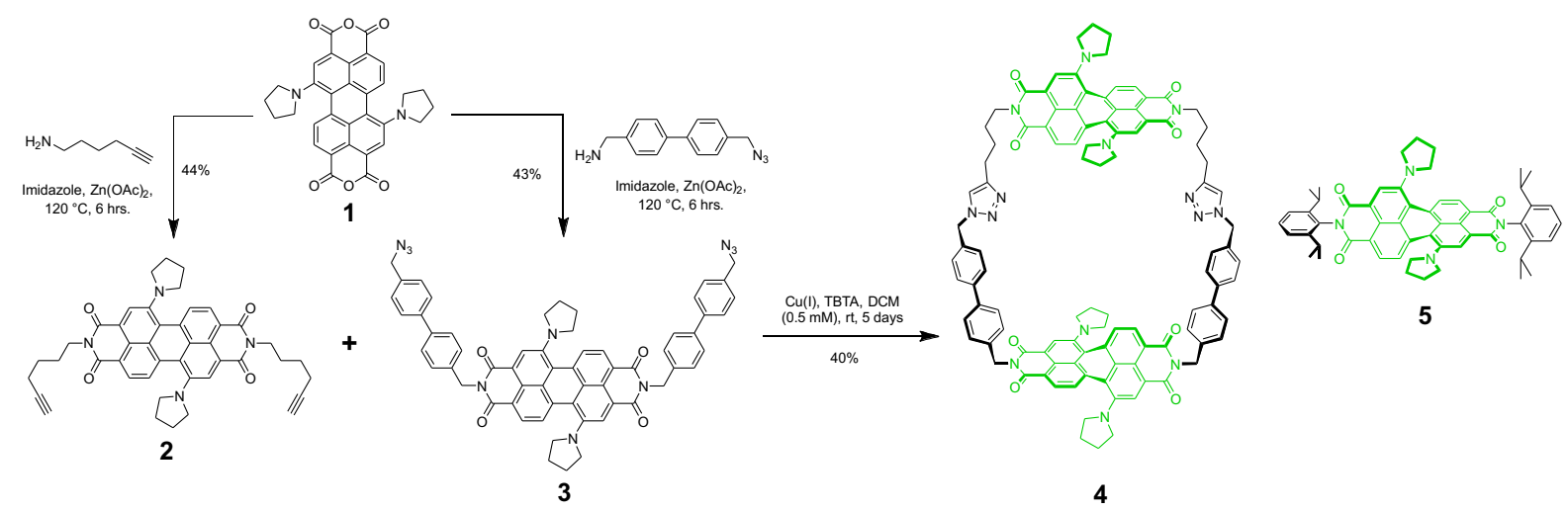

Scheme 1. Final procedures in the multi-step synthesis of bis-PDI macrocycle Green Box 4, and bispyrrolidine PDI single panel 5.

Green Box 4 was fully characterised by ${ }^{1} \mathrm{H}$ and ${ }^{13} \mathrm{C}$ NMR spectroscopy with full assignment of spectra provided from two-dimensional NMR experiments including COSY, ROESY and HSQC whilst MALDI-TOF mass spectrometry further confirmed isolation of the desired [1+1] macrocyclic product (Figure 2a and Supporting Information sections 1-3). Cyclic voltammetry of 4 recorded in nitrobenzene revealed two quasireversible oxidation processes $\left(\mathrm{E}^{1 / 2}\right.$ ox $\left.=+0.19 \mathrm{~V} ;+0.33 \mathrm{~V}\right)$, and no reduction processes within the examined potential window (Figure $2 \mathrm{~d}$ and Supporting Information section 5). Comparison of the position of these redox couples with those reported in the literature for structurally similar PDI derivatives, ${ }^{79,84,85}$ as well as the single PDI

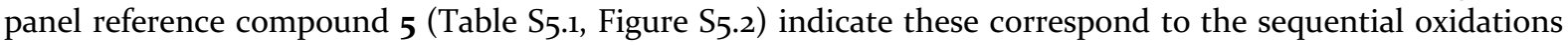
of both PDI units, thus demonstrating the electron-rich nature of the PDI macrocycle. 


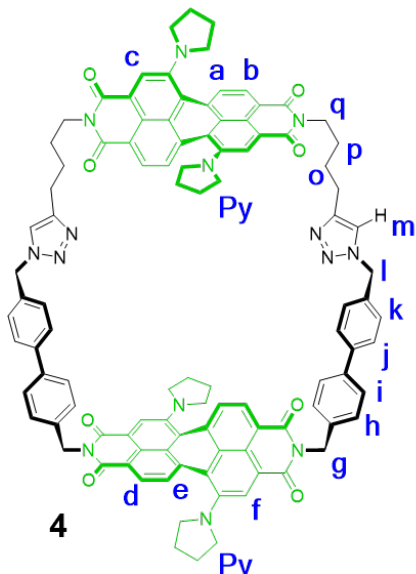

b)

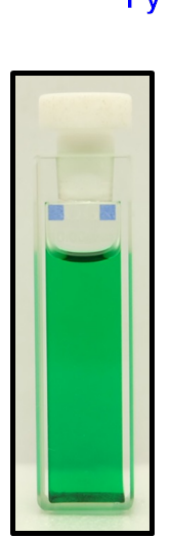

c)

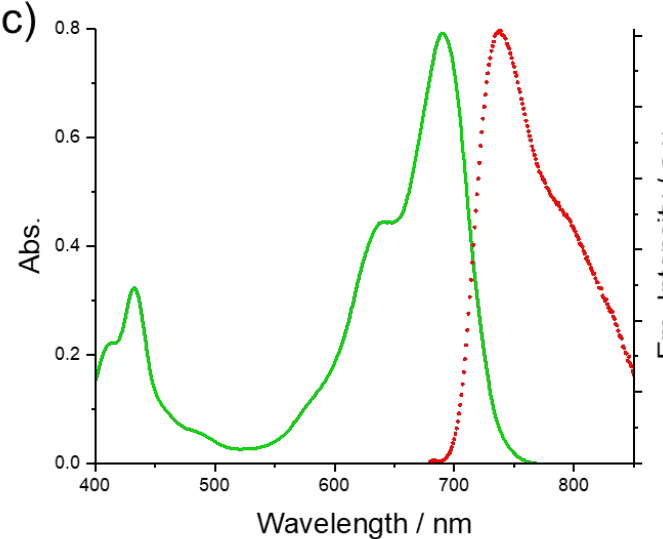

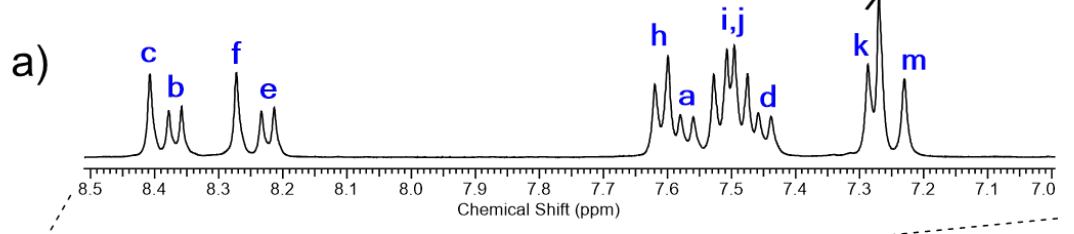

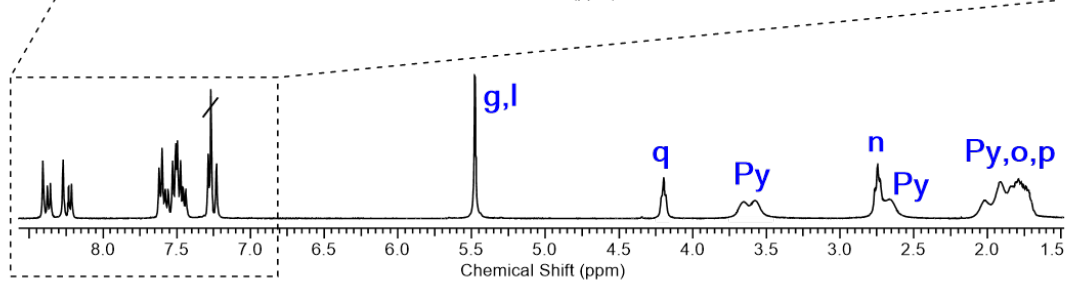

d)

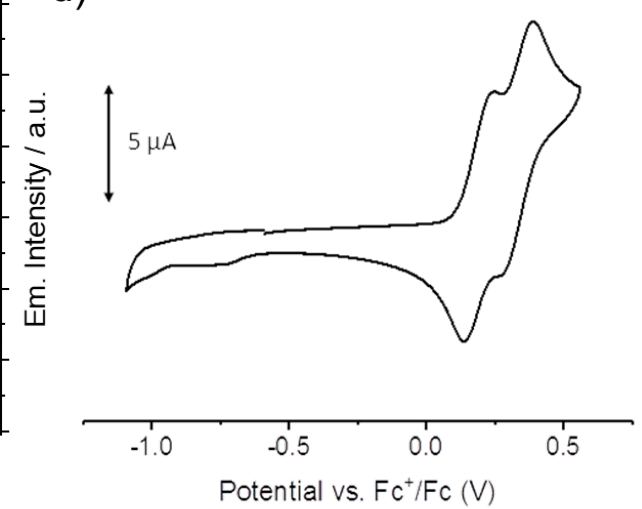

Figure 2. Characterisation of Green Box 4; (a) ${ }^{1} \mathrm{H}$ NMR spectrum $\left(\mathrm{CDCl}_{3}, 298 \mathrm{~K}, 500 \mathrm{MHz}\right)$, (b) photograph of a toluene solution $\left(10^{-4} \mathrm{M}\right)$, (c) electronic absorption (solid line) and fluorescence emission (dotted line) spectra (toluene, $10^{-5} \mathrm{M}, \lambda_{\mathrm{ex}}=68 \mathrm{omm}$ ) and (d) cyclic voltammogram (nitrobenzene with o.1 $\mathrm{M}\left[n-\mathrm{Bu}_{4} \mathrm{~N}\right]\left[\mathrm{BF}_{4}\right]$, $0.1 \mathrm{~V} / \mathrm{s})$.

Importantly, an absence of broadening of the ${ }^{1} \mathrm{H}$ NMR spectrum in $\mathrm{CDCl}_{3}$ up to a maximum concentration of $9 \mathrm{mM}$ indicated that the macrocycle remains monomeric in solution due to the twisted PDI panels (Figure 2a). This was also the case in a number of aromatic organic solvents; electronic absorption and fluorescence emission spectra of the Green Box revealed a well-resolved vibronic fine structure to respective $S_{0} \rightarrow S_{1}$ and $\mathrm{S}_{1} \rightarrow \mathrm{S}_{\mathrm{o}}$ PDI bands ${ }^{91}$ at $\lambda>600 \mathrm{~nm}$ (Figure $2 \mathrm{C}$ and Supporting Information section 4$) .{ }^{77,92}$ (Add 10.1016/j.chemphys.2006.07.023 to this ref) Interestingly, the UV-Vis-NIR spectrum of 4 also exhibited solvatochromism (Figure S4.1); with an increase in polarity producing a bathochromic shift in $\lambda_{\text {abs,max }}$ due to the PDI HOMO being localized mainly on the pyrrolidine nitrogen atoms thus giving rise to charge transfer character of the $S_{0} \rightarrow S_{1}$ transition..$^{8}$ A significant Stokes shift $(\lambda=46 \mathrm{~nm})$ is indicative of the propeller-type contortion of the aromatic framework of the macrocycle bay-substituted PDI motif (Figure 2c). ${ }^{49}$

\section{Fullerene recognition studies}

\section{Tolvene and o-dichlorobenzene}

The solution phase interactions of the Green Box with the two most ubiquitous fullerenes, $\mathrm{C}_{60}$ and $\mathrm{C}_{70}$, were investigated by a variety of techniques. Initially these studies were performed in toluene and odichlorobenzene (o-DCB) media because these aromatic solvents are known to provide excellent solubilisation of fullerenes. ${ }^{93}$

Photophysical titration experiments were performed in which up to 170 equivalents of fullerene guest were added to a solution of Green Box (host concentration maintained at $10 \mu \mathrm{M}$ ) and monitored by Vis-NIR absorption and fluorescence emission spectroscopies (Figure 3a and Supporting Information section 4)..$^{94}$ In all cases the addition of fullerene caused a significant decrease in intensity of the main $S_{0} \rightarrow S_{1}$ PDI band $\left(\lambda_{\mathrm{abs}, \max }=690 \mathrm{~nm}\right.$ in toluene) and the emergence of new absorptions at $\lambda<615 \mathrm{~nm}$ and $\lambda>730 \mathrm{~nm}$ (Figures $3 \mathrm{a}$ and S4.2 - S4.4). These are diagnostic of new ground state charge transfer aromatic stacking interactions between the tightly associating electron rich macrocyclic host and electron deficient fullerene guest, i.e. 
formation of complex $[4] \subset\left[\mathrm{C}_{60 / 70}\right] .^{34,49,54,78,79}$ Concomitant quenching of the PDI fluorescence emission (up to $29 \%{ }^{95}$ ) was also observed with $\mathrm{C}_{60}$ (Figure $3 \mathrm{a}$ ), indicative of intermolecular charge transfer between proximal donor and acceptor molecules (vide infra). ${ }^{36,49,77,78,96}$

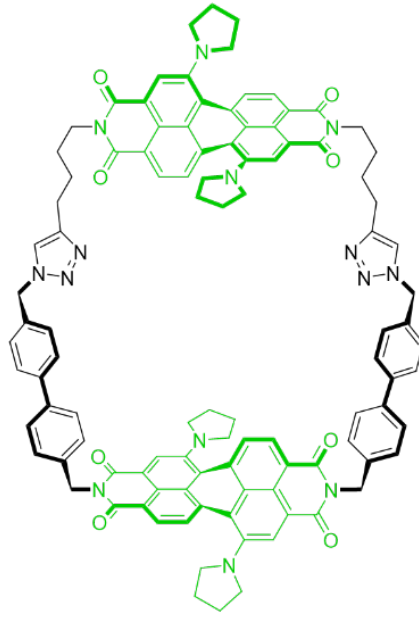

a)

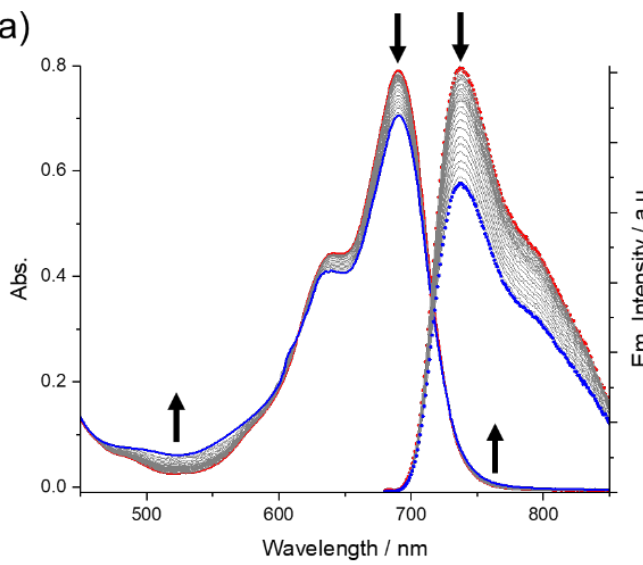

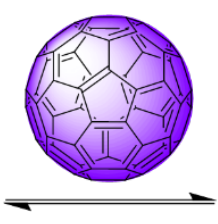

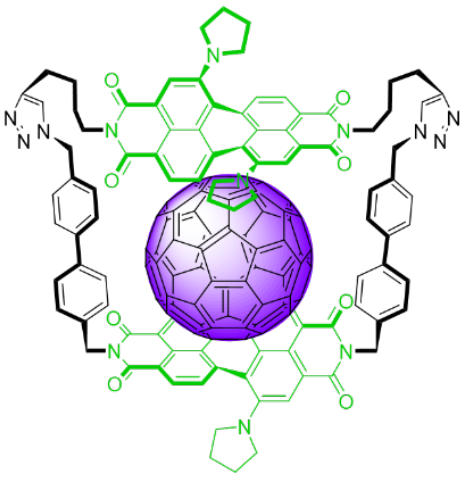

$[4]^{\delta+} \subset\left[\mathrm{C}_{60 / 70}\right]^{\delta-}$ b)

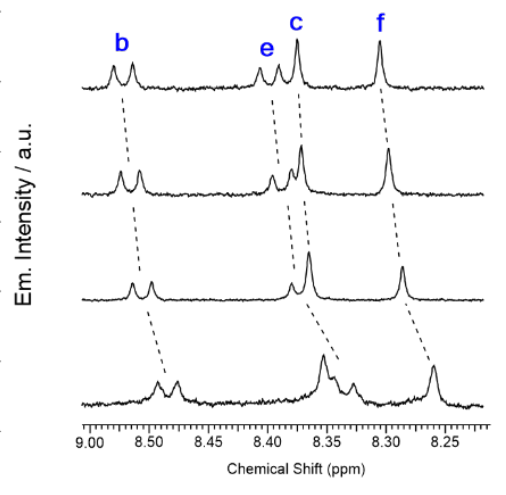

c)

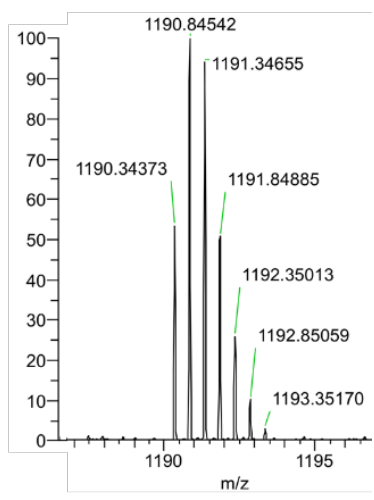

Figure 3. Characterisation of the $[4]^{\delta+} \subset\left[\mathrm{C}_{60}\right]^{\delta-}$ complex in toluene; (a) electronic absorption (solid line) and fluorescence emission (dotted line) spectra of Green Box upon the titration with $\mathrm{C}_{60}$ (170 eq., toluene, $10^{-5} \mathrm{M}$, $\lambda_{\mathrm{ex}}=680 \mathrm{~nm}$, corrected for $\mathrm{C}_{6 \mathrm{o}}$ absorptions, red line $=$ start point, blue line = end point), (b) ${ }^{1} \mathrm{H}$ NMR spectroscopic titration of up to three equivalents of $C_{60}$ into Green Box $\left(d_{8}\right.$ - toluene, [4] = 0.5 mM, $298 \mathrm{~K}, 500$ $\mathrm{MHz})$ and (c) ESI mass spectrum indicating formation of a 1:1 stoichiometric complex $\left(\mathrm{m} / \mathrm{z}=\left[4+\mathrm{C}_{60}+2 \mathrm{H}\right]^{2+}\right)$.

The formation of several isosbestic points in the Vis-NIR titration spectra $\left(\lambda_{\text {abs }}=730,615,454 \mathrm{~nm}\right.$ in toluene) indicated the establishment of a thermodynamic equilibrium between host, guest and complex $[4] \subset\left[\mathrm{C}_{60 / 70}\right]$ (Figures za and $\mathrm{S}_{4.2}-\mathrm{S}_{4} .4$ ), thereby enabling quantification of fullerene binding in solution (Table 1 ). Multiwavelength fitting at $\lambda=690-720 \mathrm{~nm}$, where the largest spectral changes occurred, was performed using Bindfit ${ }^{97}$ and revealed 1:2 host:guest stoichiometric binding (Supporting Information section 8)..$^{8}$ (Add Chem Comm 2016 12792, Chem Soc Rev 20111305 in this ref) The fullerene association constants are large and comparable to analogous macrocyclic systems containing multiple porphyrin units. ${ }^{44,99} \mathrm{In}$ all cases $\mathrm{K}_{\mathrm{a} 2}$ is negligible in comparison to $\mathrm{K}_{\mathrm{al}}$, indicating the first and most favourable binding event occurs inside the cavity of the preorganised host such that the fullerene guest is sandwiched between the two PDI units via the formation of strong charge transfer aromatic stacking interactions. The importance of a macrocyclic scaffold to facilitate such cooperativity for fullerene recognition was further highlighted when the single bispyrrolidine PDI panel of the Green Box 5 was titrated with $\mathrm{C}_{60}$ in toluene and produced negligible changes to its electronic absorption spectrum (Figure $\mathrm{S}_{4.5}$ ). ${ }^{100}$ Finally, the formation of a strong 1:1 host-guest stoichiometric complex was confirmed by mass spectrometry in which only peaks corresponding to the $\mathrm{m} / \mathrm{z}$ of the Green Box and a single $C_{60}$ fullerene species, i.e. $[4] \subset\left[C_{60}\right]$, were observed (Figures $3 c$ and $S_{3.2}$ ).

In both solvents Green Box exhibits a preference for $C_{70}$ over $C_{60}$ which may result from a closer size and shape match with the larger ellipsoidal fullerene as well as enhanced electronic complementarity owing to $C_{70}$ 
being more electron deficient..$^{36,38,101}$ In agreement with previously reported solution phase fullerene recognition studies, $\mathrm{C}_{60}$ binding is stronger in toluene than o-DCB due to the fact that the latter is a more competitive solvent. ${ }^{54,102}$ (Add J. Phys. Chem., 1993, 97, 3379 to this ref) However, on moving to the more polar solvent with $C_{70}$, an enhanced stabilisation of the stronger charge transfer aromatic stacking interactions appears to compensate for this effect. ${ }^{103,104}$ (Add CEJ 201414403 to this ref)

Table 1. Fullerene association constants $\left(\mathrm{M}^{-1}\right)$ for Green Box 4. Determined by Vis-NIR spectroscopy, errors < $5 \%\left(298 \mathrm{~K}, \lambda_{\mathrm{abs}}=690-720 \mathrm{~nm},[4]=10^{-5} \mathrm{M}\right)$.

\begin{tabular}{|l|l|l|l|l|}
\hline & \multicolumn{2}{|c|}{$C_{60}$} & \multicolumn{2}{c|}{$C_{70}$} \\
\hline & $K_{\mathrm{a} 1}$ & $K_{\mathrm{a} 2}$ & $K_{\mathrm{a} 1}$ & $K_{\mathrm{a} 2}$ \\
\hline Toluene & 42,000 & $<1$ & 69,000 & 80 \\
\hline o-DCB & 21,000 & $<1$ & 72,000 & 100 \\
\hline
\end{tabular}

Proton NMR spectroscopy was employed to understand more about the locus of the fullerene in the Green Box cavity and the nature of the interactions driving their association. The titration of three equivalents of $\mathrm{C}_{60}$ into a $\mathrm{d}_{8}$-toluene host solution $(0.4 \mathrm{mM}$ ) produced downfield shifts (up to $\Delta \delta=0.05 \mathrm{ppm}$ ) of a number of resonances including aromatic PDI based protons, $\mathrm{H}_{\mathrm{b}, \mathrm{c}, \mathrm{e}, \mathrm{f}}$ (Figures $3 \mathrm{~b}$ and $\mathrm{S} 2.4$ ). Analogous perturbations of signals were also observed in the more competitive solvent $\mathrm{d}_{4}-\mathrm{O}-\mathrm{DCB}^{105}$ (Figure S2.5) and upon titration with $\mathrm{C}_{70}$ (Figure S2.6). Interestingly, the largest downfield shifts occur for proton signals associated with the biphenyl substituted PDI of the Green Box suggesting that the additional aromatic rings and rigid strap offer superior interactions with the fullerene relative to the alkyl-linked half of the cavity. Classical macrocyclic hosts such as cycloparaphenylenes ${ }^{39}$ and porphyrin-based systems ${ }^{106}$ have also reported downfield shifts upon complexation with fullerenes. As in the case of Green Box these are ascribed to $\mathrm{CH}-\pi^{107,108}$ and intimate aromatic stacking interactions with partial charge transfer to the fullerene cage resulting in deshielding of receptor protons. By contrast, a control experiment with the single acyclic bis-pyrollidine PDI panel 5 exhibited no change to its ${ }^{1} \mathrm{H}$ NMR spectrum upon titration with $\mathrm{C}_{60}$ (Figure $\mathrm{S}_{2.7}$ ).

Finally, the existence of ground state electronic communication between fullerene and the Green Box was characterised by electrochemical studies; cyclic voltammograms of macrocycle 4 and $[4] \subset\left[\mathrm{C}_{60}\right]$ were recorded in o-DCB (Table S5.1). The encapsulation of $\mathrm{C}_{60}$ by the Green Box induced an anodic shift of $20 \mathrm{mV}$ in the first

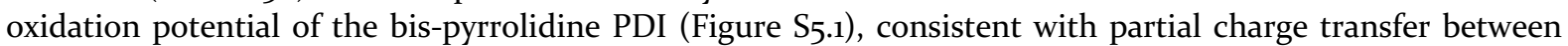
the electron donating macrocycle and electron accepting fullerene and formation of the polarized complex $[4]^{\delta+} \subset\left[\mathrm{C}_{60}\right]^{\delta-} \cdot 34,78,79,96$

Importantly all of the above techniques revealed that full ground state electron transfer to form $[4]^{++} \subset\left[\mathrm{C}_{60}\right]^{--}$ does not occur in either toluene or o-DCB. However, Green Box PDI fluorescence emission quenching by $\mathrm{C}_{60}$ (Figure 3a) and a HOMO (PDI)-LUMO $\left(\mathrm{C}_{60}\right)$ gap of $1.25 \mathrm{eV}$ (Table $\mathrm{S}_{5.1}$ ) indicated that excited state electron transfer processes were energetically favourable over formation of ${ }^{3} \mathrm{C}_{60}{ }^{*}(1.50 \mathrm{eV}) ;{ }^{109}$ with an estimated free energy change for photoinduced electron transfer from 4 to $C_{60}$ of $\Delta G_{c s}=-0.49 \mathrm{eV}$ (Supporting Information section 9a). This motivated further investigation into the excited state behaviour of the Green Box- $C_{60}$ fullerene complex in toluene, ${ }^{34}$ using LASER pulses in time resolved EPR spectroscopy (TR-EPR) with CW detection (Figure $4 \mathrm{a}, \mathrm{b}$ and Supporting Information section 6). At $\lambda_{\mathrm{ex}}=600 \mathrm{~nm}$ selected for PDI, the charge separated state $[4]^{+} \subset\left[\mathrm{C}_{60}\right]^{--}$is produced exclusively (Figure $4 \mathrm{a}$ ), with both Green Box host and fullerene guest radical ion species clearly resolved, in a peak-to-peak signal width of $6 \mathrm{mT}$ and an absorption-emission (AE) non-Boltzmann, spin polarization pattern. By contrast, in a sample of only PDI macrocycle 4, a signal width of $50 \mathrm{mT}$ with EEEAAA pattern was observed, characteristic of a molecular triplet state formed via intersystem crossing (Figure $4 \mathrm{~b}$ ). Therefore, in the absence of $\mathrm{C}_{60}$ fullerene acceptor guest, no photoinduced electron transfer processes occur. This represents a rare application of TR-EPR to probe excited state interactions of a supramolecular pristine fullerene complex.

The molecular triplet simulation gives $\mathrm{g}=\mathbf{2 . 0 0 1 8}$ and zero-field splitting values of $|\mathrm{D}|=723 \pm 5 \mathrm{MHz}$ and $|\mathrm{E} / \mathrm{D}|$ at the rhombic limit of $1 / 3$. The lineshape of the photogenerated charge separated state complex 
$[4]^{+} \subset\left[\mathrm{C}_{60}\right]^{--}$at $85 \mathrm{~K}$ does not exhibit the typical alternating EAEA shoulders from parallel dipolar coupling, indicating rotational of the dipolar interaction on the timescale of the measurement. While there is difference in polarization at W-band consistent with the case of short lived precursors, ${ }^{110}$ the individual radicals are not resolved at the higher frequency and the data may be simulated by rapid spin-spin relaxation of the $\mathrm{C}_{60}$ component (see Figure S6.4).

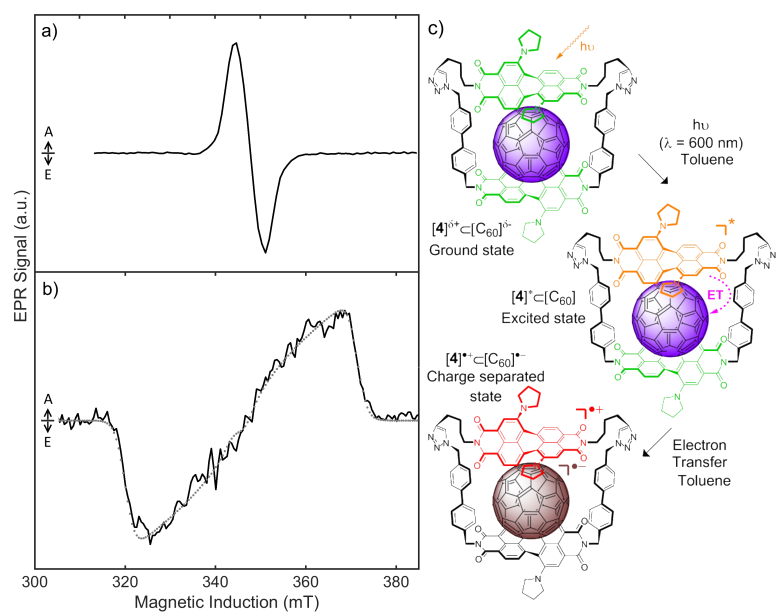

Figure 4. TR-EPR spectra of complex $[4] \subset\left[\mathrm{C}_{60}\right]$, forming $[4]^{++} \subset\left[\mathrm{C}_{60}\right]^{--}$upon excitation $\left(\lambda_{\mathrm{ex}}=600 \mathrm{~nm}\right)$ at $(\mathrm{a}) \mathrm{X}-$ band and (b) the host bis-PDI Green Box 4 (100 mM, $85 \mathrm{~K}$, in frozen toluene), black, and triplet state simulation in grey dots, with microwave absorption (A, up arrows) and emission ( $E$, down arrows) indicated in each panel. The microwave frequencies were $9.7313 \mathrm{GHz}$ in (a) and $9.6898 \mathrm{GHz}$ in (b). A schematic summarising the excited state behaviour of Green Box-fullerene complex $[4] \subset\left[C_{60}\right]$ in toluene is shown in (c).

\section{Nitrobenzene}

The formation of a supramolecular complex between Green Box and fullerene was also investigated in nitrobenzene because this solvent is significantly more polar than toluene and o-DCB $(\varepsilon=35.7$ vs. $\varepsilon=2.4$ and 9.9 respectively) whilst still able to solubilise $C_{60 / 70}{ }^{93}$ The titration of up to ten equivalents of $C_{60}$ into a $10 \mu \mathrm{M}$ solution of Green Box in nitrobenzene was monitored by Vis-NIR absorption and fluorescence emission spectroscopies (Figures 5c,d and S4.7). In this solvent perturbations to the electronic absorption spectrum were far more drastic than those observed in toluene or o-DCB and occurred at guest concentrations two orders of magnitude lower $(10 \mu \mathrm{M}$ vs $1000 \mu \mathrm{M})$ such that the addition of only one equivalent of $\mathrm{C}_{60}$ fullerene (purple solution) caused a colour change from green to brown that was visible to the naked eye (Figure 5a). Upon increasing concentration of $\mathrm{C}_{60}$ the fullerene-corrected Vis-NIR spectrum undergoes a large decrease in intensity of the main PDI absorption band $\left(S_{0} \rightarrow S_{1}\right.$ transition, $\left.\lambda_{\text {abs, } \max }=712 \mathrm{~nm}\right)$ with new bands appearing at $\lambda_{\mathrm{abs}}>800 \mathrm{~nm}$ and $\lambda_{\mathrm{abs}}<575 \mathrm{~nm}$ and two isosbestic points formed at $\lambda_{\mathrm{abs}}=582$ and $765 \mathrm{~nm}$ (Figure $5 \mathrm{c}$ ). Within the NIR region (Figure $5 \mathrm{~d}$ ) the main new absorption peaks at $\lambda_{\mathrm{abs}}=890,945$ and $1035 \mathrm{~nm}$ as well as that at $\lambda_{\mathrm{abs}}$ $=542 \mathrm{~nm}$ are ascribed to a bis-pyrrolidine PDI radical cation species, [PDI $]^{+1},{ }^{111}{ }^{-113}$ (See more refs to be added) whilst the broad band at $\lambda_{\text {abs }} \sim 1100 \mathrm{~nm}$ is characteristic of $\mathrm{C}_{60}$ radical anion, $\left[\mathrm{C}_{60}\right]^{-1} \cdot{ }^{103,114-116}$ 
a)

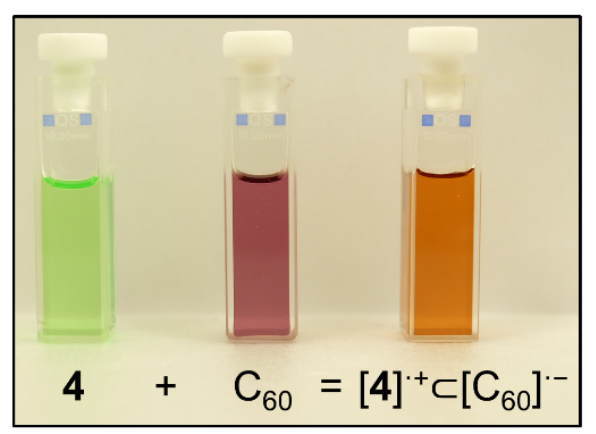

c)

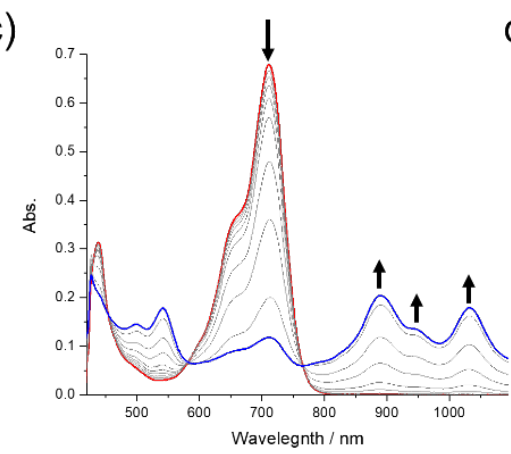

d)

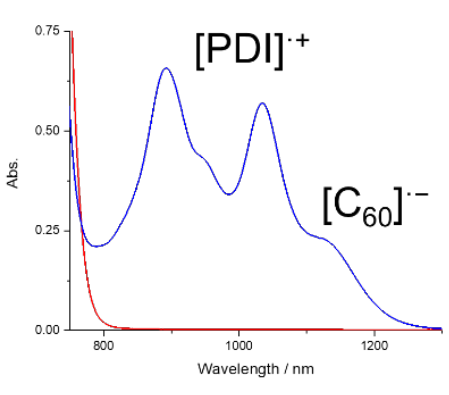

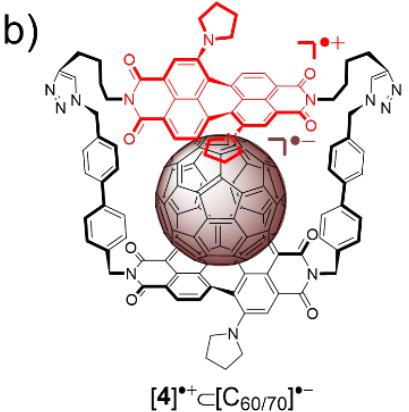

e)

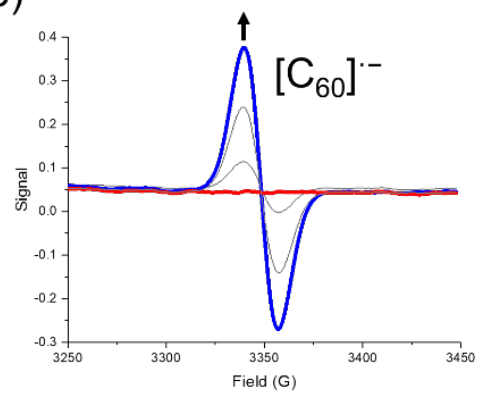

Figure 5. Characterisation of the $[4]^{++} \subset\left[\mathrm{C}_{60}\right]^{--}$complex in nitrobenzene; (a) Photograph showing naked eye colour change upon mixing of equimolar solutions of Green Box and $\mathrm{C}_{60}$ in nitrobenzene $\left(10^{-4} \mathrm{M}\right)$, (b) structure of the charge separated radical ion paired complex, (c) Vis-NIR electronic absorption spectra of Green Box upon titration with $\mathrm{C}_{60}$ (10 eq., nitrobenzene, $10^{-5} \mathrm{M}$ ), (d) NIR absorption spectrum after 1 eq. $\mathrm{C}_{60}$ $\left(10^{-4} \mathrm{M}\right)$ and (e) EPR spectra of Green Box upon titration with $\mathrm{C}_{60}$ (4 eq., nitrobenzene, $\left.10^{-4} \mathrm{M}\right)$. All Vis-NIR spectra corrected for $\mathrm{C}_{60}$ absorptions, red line $=$ start point, blue line $=$ end point.

The formation of $\mathrm{C}_{60}$ radical anion was further characterised by electron paramagnetic resonance (EPR) spectroscopy; the titration of up to four equivalents of $C_{60}$ into a nitrobenzene solution of Green Box 4 generated a single resonance ( $\mathrm{g}$-factor $=\mathbf{2 . 0 0 2}$ ), with signal intensity increasing after each addition (Figure 5e). An Easyspin fit of the data revealed a peak-to-peak line width (LWpp) of 17.4G. These observations are consistent with literature values calculated for chemically and electrochemically generated $C_{60}$ radical anions. ${ }^{117-121}$ The line shape is substantially Gaussian in character, with a small (10\%) Lorentzian component. Importantly, identical Vis-NIR absorption and EPR spectral changes occurred when mixing of macrocycle 4 and $\mathrm{C}_{60}$ was performed in the absence of light whilst control experiments using these spectroscopies revealed no radical ion species were present in nitrobenzene solutions of host or guest prior to their combination (Figures S4.9 and S6.1).

Remarkably, these results all evidence the occurrence of a thermally promoted, ground state single electron transfer (SET) from the electron rich bis-pyrrolidine PDI donor (D) to an electron deficient $\mathrm{C}_{60}$ fullerene cage acceptor (A) upon its tight encapsulation (as a radical anion) within the Green Box (Figure $5 \mathrm{~b}$ ). ${ }^{122,123}$ Whilst only partial charge transfer was observed in toluene and o-DCB solvents (vide supra, Figure 3), the significantly higher polarity of nitrobenzene now facilitates full ground state electron transfer and formation of a novel charge separated $[4]^{+} \subset\left[C_{60}\right]^{--}$complex. Ground state SET to $C_{60}$ is extremely rare, with examples limited to simple secondary and tertiary amine donors ${ }^{16,124,125}$ such as 1,3-diaminepropane ${ }^{115}$ or with endohedral metallofullerene (EMF) acceptors with more favourable reduction potentials than their empty cage analogues. ${ }^{12,125}$ Indeed, to the best of our knowledge, Green Box is the first rationally designed synthetic receptor capable of recognising and sensing a pristine fullerene via thermally promoted SET from host to guest, with previous systems reporting only evidence of partial charge transfer in the ground state. ${ }^{33,34,47,49,52,54,126-128}$

Most importantly, SET occurs under ambient conditions; i.e. at room temperature, in oxygenated solvent and is unaffected by natural light (i.e. not a photoinduced process). The robustness of this process was also demonstrated when analogous Vis-NIR spectral changes were observed in titrations with $C_{70}\left(\left[C_{70}\right]^{-}\right.$, $\lambda_{\text {abs }}$ $1150 \mathrm{~nm}$, Figure $\left.\mathrm{S}_{4} .8\right)$ and with $\mathrm{C}_{60}$ under more dilute conditions ( $1 \mu \mathrm{M}$ host solution, Figure $\left.\mathrm{S}_{4} .6\right)$. As expected, the formation of new radical ion species in solution results in an almost complete quenching of 
Green Box PDI excited state fluorescence emission (90 \% ${ }^{95}$ ) upon addition of fullerene (Figure S4.7) ${ }^{77}$ Further evidence for the formation of $[4]^{++} \subset\left[\mathrm{C}_{60}\right]^{-}$radicals was provided by significant broadening of resonances, predominantly PDI protons $\left(\mathrm{H}_{\mathrm{b}, \mathrm{c}, \mathrm{e}, \mathrm{f}}\right)$, in the ${ }^{1} \mathrm{H}$ NMR spectrum (Figure $\left.\mathrm{S} 2.8\right)$.

The formation of isosbestic points in the Vis-NIR spectra (Figure 5c) indicate the formation of a thermodynamic equilibrium between the 'neutral' and charge separated radical ion paired complexes, $[4]^{\delta+} \subset\left[\mathrm{C}_{60}\right]^{\delta-}$ and $[4]^{-+} \subset\left[\mathrm{C}_{60}\right]^{--}$respectively. To investigate whether SET between Green Box and $\mathrm{C}_{60}$ fullerene is a truly reversible process, the Vis-NIR electronic absorption spectrum of the host-guest complex was measured in increasingly polar nitrobenzene:toluene solvent mixtures at equimolar concentrations (Figure 6). Increasing or decreasing the proportion of the more polar solvent caused a gradual increase or decrease in intensity of NIR peaks associated with the radical ion pairs $\left(\lambda_{\mathrm{abs}}=890,945,1035\right.$ and $\left.\sim 1100 \mathrm{~nm}\right)$ thereby confirming the existence of thermodynamic equilibrium and a clear solvatochromism to the charge separated state/dependence on solvent permittivity. ${ }^{122}$ Further evidence for the reversible nature of electron transfer, and therefore the stability of the resulting radical species in $[4]^{++} \subset\left[\mathrm{C}_{60}\right]^{--}$, was gained from kinetic studies in solution (vide infra).

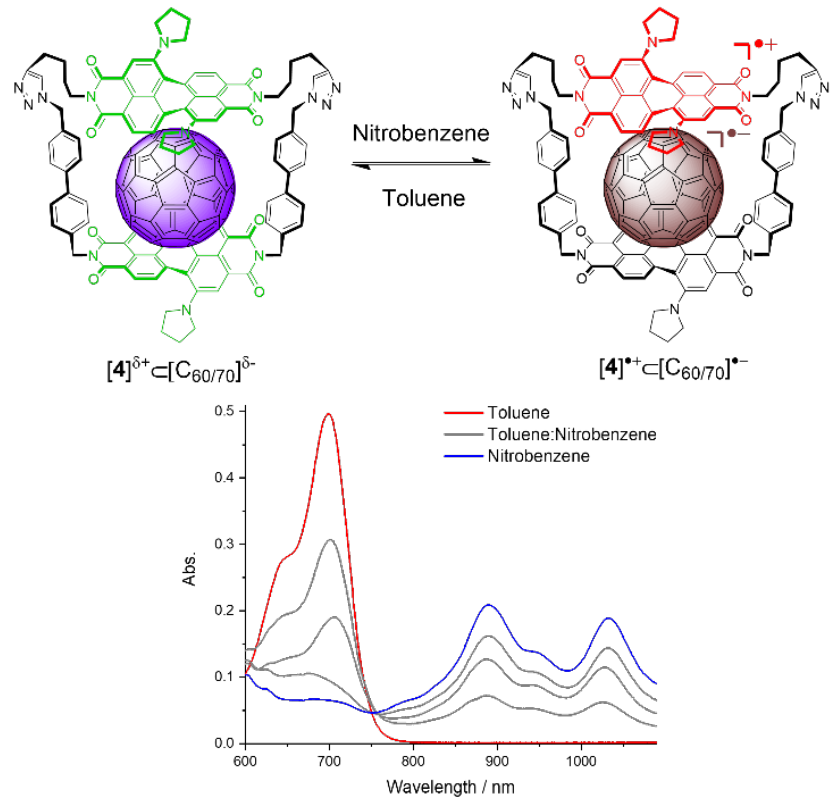

Figure 6. Vis-NIR electronic absorption spectra of $[4]^{++} \subset\left[\mathrm{C}_{60}\right]^{--}$measured in toluene:nitrobenzene mixtures demonstrates thermodynamic equilibrium controlled by solvent polarity $\left(10^{-5} \mathrm{M}\right)$.

The respective oxidation and reduction potentials of the Green Box host donor and $\mathrm{C}_{60}$ fullerene guest acceptor (Table S5.1) can be used to estimate a free energy change for SET of $\Delta \mathrm{G}_{\mathrm{et}}=24 \mathrm{kcal} \mathrm{mol}^{-1}$ via the Rehm-Weller equation (Supporting Information section $9 \mathrm{~b}$ ). ${ }^{129}$ The positive value signifies that full electron transfer (i.e. formation of $[4]^{+} \subset\left[\mathrm{C}_{60}\right]^{--}$) is thermodynamically unfavourable, however, as shown experimentally it still occurs at room temperature which therefore suggests that it is the extremely strong association between macrocyclic host and fullerene guest (i.e. formation of $[4] \subset\left[C_{60}\right]$, see Supporting Information section $9 \mathrm{~b}$ ), alongside the permittivity of the solvent, that promotes a spontaneous redox process. ${ }^{103,130,131}$ (Add JACS 201711008 as a ref here) Furthermore, previous studies have observed ground state electron transfer from electron rich azacrown ${ }^{125}$ or thiacrown ether ${ }^{130}$ donors to fullerenes despite energetic penalties similar to that calculated for the Green Box. ${ }^{132}$ Whilst electron transfer to $C_{70}$ will be thermodynamically more favourable owing to its less negative reduction potential, switching the solvent to oDCB increases the free energy barrier $\left(\Delta \mathrm{G}_{\mathrm{et}} \sim 28 \mathrm{kcal} \mathrm{mol}^{-1}\right.$ with $\left.\mathrm{C}_{6 \mathrm{o}}\right)$ because the solvent's lower polarity leads to less favourable redox potentials (Table $\mathrm{S}_{5.1}$ ) and weaker stabilisation of the charge separated state complex $[4]^{++} \subset\left[\mathrm{C}_{60}\right]^{--}$.

EPR spectroscopy revealed that $\mathrm{C}_{60}{ }^{--}$was persistent in a solution of complex $[4]^{++} \subset\left[\mathrm{C}_{60}\right]^{--}$in nitrobenzene on the benchtop under ambient conditions for longer than two weeks (Figure S6.2), albeit with a lower signal intensity than at the start. This remarkable durability of the radical ions in solution prompted a more detailed kinetic study by Vis-NIR absorption, EPR and NMR spectroscopies. A time course measurement of 
the electronic absorption band associated with $[\mathrm{PDI}]^{+}$at $\lambda_{\mathrm{abs}}=890 \mathrm{~nm}$ of a 1:5 host:guest stoichiometric mixture revealed fast SET followed by a slow decrease in concentration of this species over seven hours, ${ }^{123,133,134}$ giving a PDI radical cation half-life of $t_{1 / 2}>600$ minutes with radical ions still apparent in the NIR spectrum after two days (Figure S7.1). ${ }^{135}$ Under the same conditions the time dependence of the EPR spectrum revealed similar kinetic behaviour for $\mathrm{C}_{60}{ }^{-}$(Figures S6.3, $\mathrm{S}_{7.2}$ ). Importantly, the high stability of the radical ion pairs in $[4]^{++} \subset\left[\mathrm{C}_{60}\right]^{--}$is highlighted upon comparison with previous studies into the interaction of $\mathrm{C}_{60}$ and simple organic amine donors that reported significant air and moisture sensitivity ${ }^{116}$ of the $\mathrm{C}_{60} \cdot{ }^{-}$generated with $t_{1 / 2}=$ $10-30$ mins. $^{133,134,136}$

After three days the complex solution returned to its original green colour (Figure $5 \mathrm{a}$ ) and the Vis-NIR absorption spectrum predominantly resembled that of the 'neutral' Green Box and $\mathrm{C}_{60}$ fullerene species, i.e. reforming $[4]^{\delta+} \subset\left[\mathrm{C}_{60}\right]^{\delta-}$ (Figure $\mathrm{S}_{4.10-4.11)}{ }^{137}$ Over the same time course, ${ }^{1} \mathrm{H}$ NMR spectroscopy revealed a gradual sharpening of Green Box proton resonances (Figure S2.9) with ${ }^{13} \mathrm{C}$ NMR (Figure S2.10) and MALDITOF mass spectra (Figure $S_{3.3}$ ) also confirming the presence of pristine $C_{60}$ fullerene whilst no new signals appeared in the EPR spectrum. Furthermore, TLC analysis of the mixture indicated only the regeneration of starting materials (via back electron transfer) so that, unlike with simple organic amine donors, ${ }^{116,125,134}$ follow up chemical reactions do not occur. The superior SET behaviour of Green Box with $\mathrm{C}_{60}$ can be related to contrasting chemical structures; it has been shown that sterically hindered tertiary amines, ${ }^{134}$ such as those present in the bis-pyrrolidine PDI panels of $\mathbf{4}$, produce a more persistent spin density in solution than secondary or less bulky amines ${ }^{16,125,134}$ for which new covalent bond forming reaction pathways can compete. $^{138}$

Importantly, there was no time dependence to the spectral changes arising from charge transfer interactions in toluene solution, signifying the resilience of the polarised complex $[4]^{\delta+} \subset\left[\mathrm{C}_{60}\right]^{\delta-}$ (Figure S7.3). Therefore, the contrasting electronic behaviour of the Green Box receptor serves to highlight the importance of solvent on not only dictating the thermodynamics (partial charge transfer vs. full electron transfer) but also the kinetics (stability of each complex type) involved in the non-covalent recognition of fullerenes.

\section{Conclusions}

This work describes the rational design, synthesis and in-depth $\mathrm{C}_{60 / 70}$ fullerene recognition investigation of a novel macrocycle which, due to the two bis-bay substituted pyrrolidine-perylene diimide-based panels, is nicknamed the "Green Box" 4. Aryl and alkyl spacer units that separate the two twisted aromatic PDI surfaces act to create a rigid yet size-adaptable, electron rich cavity capable of encapsulating electron deficient fullerene guests such as $C_{60}$ or $C_{70}$ to form a supramolecular complex, $[4] \subset\left[C_{60 / 70}\right]$. Importantly, strong solution phase fullerene recognition (millimolar affinity) was shown to occur exclusively within this macrocyclic receptor framework and not to an acyclic single PDI panel 5. Characterisation of the complex and the fundamental non-covalent interactions that drive its formation were elucidated through a variety of techniques including electronic absorption, fluorescence emission, NMR and EPR spectroscopies, electrochemistry and mass spectrometry.

The electronic complementarity between Green Box PDI receptor and fullerene guest was manifested in ground state partial charge transfer in toluene and o-DCB solution $\left([4]^{\delta+} \subset\left[\mathrm{C}_{60 / 70}\right]^{\delta-}\right)$, with such chromogenic interactions in part responsible for an enhancement in binding of the more electron deficient $C_{70}$ over $C_{60}$. To the best of our knowledge, this is the first report of intermolecular electronic communication in the ground state between perylene diimide and fullerene. Therefore, alongside more renowned aromatic derivatives such as porphyrin, ${ }^{44,128}$ cycloparaphenylene ${ }^{39,139}$ and tetrathiafulvalene, ${ }^{140,141}$ twisted electron rich PDIs are introduced as new motifs for fullerene recognition.

Whilst time resolved EPR spectroscopy revealed that complete single electron transfer between Green Box donor and fullerene acceptor only occurred via the excited state in toluene (a rare application of the technique for this purpose), switching the solvent to nitrobenzene stimulated intermolecular ground state SET without the need for photoirradiation under ambient conditions. ${ }^{16,123}$ Facilitated by an exceptionally strong association between donor and acceptor, thermally allowed SET within a supramolecular hostfullerene guest complex is unprecedented behaviour unique to the Green Box host. From the ensuing radical ion pair, both $[\mathrm{PDI}]^{++}$(chemically generated for the first time in solution) and $\left[\mathrm{C}_{60}\right]^{-}$species were characterised by Vis-NIR electronic absorption and EPR spectroscopies, and were shown to be remarkably bench-stable with $\left[\mathrm{C}_{60}\right]^{--}$still present in solution after two weeks. Importantly, a dependence on solvent permittivity revealed the charge-separated state complex $[4]^{++} \subset\left[\mathrm{C}_{60}\right]^{--}$to exist in thermal equilibrium with its polarised partial charge transfer analogue $[4]^{\delta+} \subset\left[\mathrm{C}_{60}\right]^{\delta-}$. Such reversible electron transfer processes play a key 
role in biological energy conversion. ${ }^{18}$ The above provides a rare example of an artificial supramolecular donor-acceptor ensemble ${ }^{123}$ in which a solvent stimulus is used to switch between two extremes of the energy continuum, ${ }^{55}$ to promote either charge separation or recombination, in similar fashion to cofactors found in natural systems. ${ }^{122-144}$

In summary, Green Box permits intermolecular, tuneable partial charge or full electron transfer in the ground state to pristine fullerenes, the former being unprecedented with perylene diimides and the latter any synthetic fullerene-based dyad system (Figure 7). This generates a biomimetic supramolecular ensemble that undergoes reversible electron transfer processes. Further investigation into the applications of this unique PDI donor-fullerene acceptor behaviour within molecular organic electronics and optical carbon nanomaterials or functional devices, including new routes to fullerene purification, are currently ongoing.

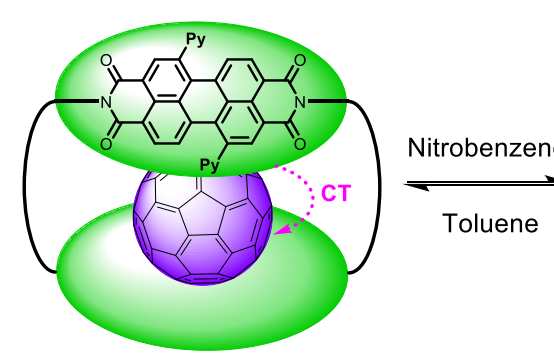

$[4]^{\delta+}\left[\mathrm{C}_{60 / 70}\right]^{\delta-}$

Ground state charge transfer (CT) Excited state electron transfer (ET)

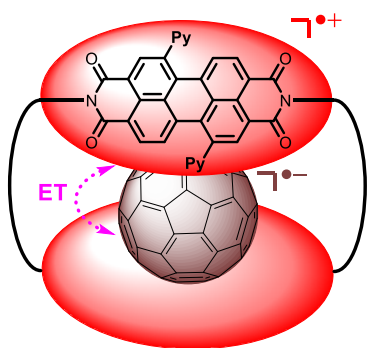

$[4]^{0+}\left[\mathrm{C}_{60 / 70}\right]^{\circ-}$

Ground state electron transfer

Figure 7. Schematic showing the solvent tuneable ground and excited state electronic interactions of the non-covalent Green Box donor-fullerene acceptor complex.

\section{Associated Content}

Further details of synthetic procedures, characterization, electrochemical and spectroscopic data and additional discussion including Schemes, Figures and Tables are included in the Supporting Information (Sections 1-9).

\section{Author Information}

Corresponding Authors

*timothy.barendt@chem.ox.ac.uk

*paul.beer@chem.ox.ac.uk

ORCID:

Paul D. Beer: oooo-0oo3-0810-9716

Timothy A. Barendt: oooo-0oo2-9806-4381

Maria A. Lebedeva: oooo-ooo2-3543-6416

William K. Myers: oooo-ooo1-5935-9112

Acknowledgements

T.A.B. thanks Christ Church and the John Fell Fund, University of Oxford for funding. W.K.M. is supported by UK EPSRC (EP/Lo11972/1), grant to Centre for Advanced ESR, CAESR

\section{References}


(1) Langa, F.; Nierengarten, J.-F. Fullerenes: Principles and Applications; Royal Society of Chemistry, 2007.

(2) Delgado, J. L.; Herranz, M. Á.; Martín, N. The Nano-Forms of Carbon. J. Mater. Chem. 2008, 18 (13), 1417-1426. https://doi.org/10.1039/B717218D.

(3) Collavini, S.; Delgado, J. L. Fullerenes: The Stars of Photovoltaics. Sustain. Energy Fuels 2018. https://doi.org/10.1039/C8SE00254A.

(4) Delgado, J. L.; Bouit, P.-A.; Filippone, S.; Herranz, M. Á.; Martín, N. Organic Photovoltaics: A Chemical Approach. Chem. Commun. 2010, 46 (27), 4853-4865. https://doi.org/10.1039/C003088K.

(5) Castro, E.; Murillo, J.; Fernandez-Delgado, O.; Echegoyen, L. Progress in FullereneBased Hybrid Perovskite Solar Cells. J. Mater. Chem. C 2018, 6 (11), 2635-2651. https://doi.org/10.1039/C7TC04302C.

(6) Grant, P. Superconductivity: Up on the $\mathrm{C}_{60}$ Elevator. Nature 2001, 413 (6853), 264265. https://doi.org/10.1038/35095149.

(7) Dagotto, E. The Race to Beat the Cuprates. Science 2001, 293 (5539), 2410-2411. https://doi.org/10.1126/science.1065711.

(8) Iwasa, Y. Superconductivity: Revelations of the Fullerenes. Nature 2010, 466 (7303), 191-192. https://doi.org/10.1038/466191a.

(9) Rašović, I. Water-Soluble Fullerenes for Medical Applications. Mater. Sci. Technol. 2017, 33 (7), 777-794. https://doi.org/10.1080/02670836.2016.1198114.

(10) Rašović, I.; Porfyrakis, K. Functionalisation of Fullerenes for Biomedical Applications. In Reference Module in Materials Science and Materials Engineering; Elsevier, 2018. https://doi.org/10.1016/B978-0-12-803581-8.11224-X.

(11) Nakamura, E.; Isobe, H. Functionalized Fullerenes in Water. The First 10 Years of Their Chemistry, Biology, and Nanoscience. Acc. Chem. Res. 2003, 36 (11), 807-815. https://doi.org/10.1021/ar030027y.

(12) Guldi, D. M.; Illescas, B. M.; Atienza, C. M.; Wielopolski, M.; Martín, N. Fullerene for Organic Electronics. Chem. Soc. Rev. 2009, 38 (6), 1587-1597. https://doi.org/10.1039/B900402P.

(13) Martín, N.; Sánchez, L.; Herranz, M. Á.; Illescas, B.; Guldi, D. M. Electronic Communication in Tetrathiafulvalene (TTF)/C60 Systems: Toward Molecular Solar Energy Conversion Materials? Acc. Chem. Res. 2007, 40 (10), 1015-1024. https://doi.org/10.1021/ar700026t.

(14) Lebedeva, M. A.; Chamberlain, T. W.; Khlobystov, A. N. Harnessing the Synergistic and Complementary Properties of Fullerene and Transition-Metal Compounds for Nanomaterial Applications. Chem. Rev. 2015, 115 (20), 11301-11351. https://doi.org/10.1021/acs.chemrev.5b00005.

(15) D'Souza, F.; Ito, O. Supramolecular Donor-Acceptor Hybrids of Porphyrins/Phthalocyanines with Fullerenes/Carbon Nanotubes: Electron Transfer, Sensing, Switching, and Catalytic Applications. Chem. Commun. 2009, 0 (33), 49134928. https://doi.org/10.1039/B905753F.

(16) Echegoyen, L.; Echegoyen, L. E. Electrochemistry of Fullerenes and Their Derivatives. Acc. Chem. Res. 1998, $31 \quad$ (9), 593-601. https://doi.org/10.1021/ar970138v.

(17) Hiroshi, I.; Kiyoshi, H.; Tsuyoshi, A.; Masanori, A.; Seiji, T.; Tadashi, O.; Masahiro, S.; Yoshiteru, S. The Small Reorganization Energy of C60 in Electron Transfer. Chem. Phys. Lett. 1996, 263 (3), 545-550. https://doi.org/10.1016/S0009-2614(96)01244-4.

(18) The Photosynthetic Reaction Center; Deisenhofer, J., Norris, J. R., Eds.; Academic Press: San Diego, CA, 1993. 
(19) Campidelli, S.; Mateo-Alonso, A.; Prato, M. Chapter 7:Fullerenes for Material Science. In Fullerenes; 2007; pp 191-220. https://doi.org/10.1039/978184755771100191.

(20) Guldi, D. M. Fullerene-Porphyrin Architectures; Photosynthetic Antenna and Reaction Center Models. Chem. Soc. Rev. 2002, 31 (1), 22-36. https://doi.org/10.1039/B106962B.

(21) Guldi, D. M.; Giacalone, F.; Torre, G. de la; Segura, J. L.; Martín, N. Topological Effects of a Rigid Chiral Spacer on the Electronic Interactions in Donor-Acceptor Ensembles. Chem. - Eur. J. 2005, 11 (24), 7199-7210. https://doi.org/10.1002/chem.200500209.

(22) Hudhomme, P.; Williams, R. M. Energy and Electron Transfer in Photo- and ElectroActive Fullerene Dyads. In Handbook of Carbon Nano Materials; World Scientific Series on Carbon Nanoscience; WORLD SCIENTIFIC, 2011; Vol. Volume 1 \& 2, pp 545-591. https://doi.org/10.1142/9789814327824_0017.

(23) Barendt, T. A.; Rašović, I.; Lebedeva, M. A.; Farrow, G. A.; Auty, A.; Chekulaev, D.; Sazanovich, I. V.; Weinstein, J. A.; Porfyrakis, K.; Beer, P. D. Anion-Mediated Photophysical Behavior in a C60 Fullerene [3]Rotaxane Shuttle. J. Am. Chem. Soc. 2018, 140 (5), 1924-1936. https://doi.org/10.1021/jacs.7b12819.

(24) Kirner, S. V.; Henkel, C.; Guldi, D. M.; Jr, J. D. M.; Schuster, D. I. Multistep Energy and Electron Transfer Processes in Novel Rotaxane Donor-Acceptor Hybrids Generating Microsecond-Lived Charge Separated States. Chem. Sci. 2015, 6 (12), 7293-7304. https://doi.org/10.1039/C5SC02895G.

(25) Mateo-Alonso, A. Mechanically Interlocked Molecular Architectures Functionalised with Fullerenes. Chem. Commun. 2010, 46 (48), 9089-9099. https://doi.org/10.1039/C0CC03724A.

(26) Mateo-alonso, A. Fullerene-Containing Rotaxanes and Catenanes. In Supramolecular Chemistry of Fullerenes and Carbon Nanotubes; Nazariortín, Nierengarten, J.-F., Eds.; Wiley-VCH Verlag GmbH \& Co. KGaA, 2012; pp 107-126.

(27) Megiatto, Jr., J. D.; Schuster, D. I. Chapter 10. Interlocked Artificial Photosynthetic Model Systems Composed of Electron-Donor and [60]Fullerene Units. In RSC Nanoscience \& Nanotechnology; Langa De La Puente, F., Nierengarten, J.-F., Eds.; Royal Society of Chemistry: Cambridge, 2011; pp 354-385.

(28) Mateo-Alonso, A.; Ehli, C.; Rahman, G. M. A.; Guldi, D. M.; Fioravanti, G.; Marcaccio, M.; Paolucci, F.; Prato, M. Tuning Electron Transfer through Translational Motion in Molecular Shuttles. Angew. Chem. Int. Ed. 2007, 46 (19), 3521-3525. https://doi.org/10.1002/anie.200605039.

(29) Guldi, D. M.; Ramey, J.; Martínez-Díaz, M. V.; Escosura, A. de la; Torres, T.; Ros, T. D.; Prato, M. Reversible Zinc Phthalocyanine Fullerene Ensembles. Chem. Commun. 2002, $O$ (23), 2774-2775. https://doi.org/10.1039/B208516J.

(30) Segura, M.; Sánchez, L.; de Mendoza, J.; Martín, N.; Guldi, D. M. Hydrogen Bonding Interfaces in Fullerene•TTF Ensembles. J. Am. Chem. Soc. 2003, 125 (49), 1509315100. https://doi.org/10.1021/ja036358n.

(31) Herranz, M. Á.; Giacalone, F.; Sánchez, L.; Martín, N. Chapter 6:Hydrogen Bonding Donor-Acceptor Carbon Nanostructures. In Fullerenes; 2007; pp 152-190. https://doi.org/10.1039/9781847557711-00152.

(32) Electron Transfer in a Non-Covalent Donor-Acceptor Network Is as Efficient as That in a Covalent System. 
(33) Rizzuto, F. J.; Wood, D. M.; Ronson, T. K.; Nitschke, J. R. Tuning the Redox Properties of Fullerene Clusters within a Metal-Organic Capsule. J. Am. Chem. Soc. 2017, 139 (32), 11008-11011. https://doi.org/10.1021/jacs.7b05788.

(34) Moreira, L.; Calbo, J.; Calderon, R. M. K.; Santos, J.; Illescas, B. M.; Aragó, J.; Nierengarten, J.-F.; Guldi, D. M.; Ortí, E.; Martín, N. Unveiling the Nature of Supramolecular Crown Ether-C60 Interactions. Chem. Sci. 2015, 6 (8), 4426-4432. https://doi.org/10.1039/C5SC00850F.

(35) Fuertes-Espinosa, C.; García-Simón, C.; Castro, E.; Costas, M.; Echegoyen, L.; Ribas, X. A Copper-Based Supramolecular Nanocapsule That Enables Straightforward Purification of Sc3N-Based Endohedral Metallofullerene Soots. Chem. - Eur. J. 2017, 23 (15), 3553-3557. https://doi.org/10.1002/chem.201700046.

(36) Ke, X.-S.; Kim, T.; Lynch, V. M.; Kim, D.; Sessler, J. L. Flattened Calixarene-like Cyclic BODIPY Array: A New Photosynthetic Antenna Model. J. Am. Chem. Soc. 2017, 139 (39), 13950-13956. https://doi.org/10.1021/jacs.7b08611.

(37) Mahata, K.; Frischmann, P. D.; Würthner, F. Giant Electroactive M4L6 Tetrahedral Host Self-Assembled with Fe(II) Vertices and Perylene Bisimide Dye Edges. J. Am. Chem. Soc. 2013, 135 (41), 15656-15661. https://doi.org/10.1021/ja4083039.

(38) Shi, Y.; Cai, K.; Xiao, H.; Liu, Z.; Zhou, J.; Shen, D.; Qiu, Y.; Guo, Q.; Stern, C.; Wasielewski, M. R.; et al. Selective Extraction of C70 by a Tetragonal Prismatic Porphyrin Cage. J. Am. Chem. Soc. 2018. https://doi.org/10.1021/jacs.8b08555.

(39) Iwamoto, T.; Watanabe, Y.; Sadahiro, T.; Haino, T.; Yamago, S. Size-Selective Encapsulation of C60 by [10]Cycloparaphenylene: Formation of the Shortest Fullerene-Peapod. Angew. Chem. Int. Ed. 2011, 50 (36), 8342-8344. https://doi.org/10.1002/anie.201102302.

(40) Lhoták, P.; Kundrát, O. Fullerene Receptors Based on Calixarene Derivatives. In Artificial Receptors for Chemical Sensors; Wiley-Blackwell, 2010; pp 249-272. https://doi.org/10.1002/9783527632480.ch8.

(41) Pérez, E. M.; Martín, N. Curves Ahead: Molecular Receptors for Fullerenes Based on Concave-Convex Complementarity. Chem. Soc. Rev. 2008, 37 (8), 1512-1519. https://doi.org/10.1039/B802589B.

(42) Kishi, N.; Akita, M.; Yoshizawa, M. Selective Host-Guest Interactions of a Transformable Coordination Capsule/Tube with Fullerenes. Angew. Chem. Int. Ed. 2014, 53 (14), 3604-3607. https://doi.org/10.1002/anie.201311251.

(43) Nakamura, T.; Ube, H.; Miyake, R.; Shionoya, M. A C60-Templated Tetrameric Porphyrin Barrel Complex via Zinc-Mediated Self-Assembly Utilizing Labile Capping Ligands. J. Am. Chem. Soc. 2013, 135 (50), 18790-18793. https://doi.org/10.1021/ja4110446.

(44) Tashiro, K.; Aida, T. Metalloporphyrin Hosts for Supramolecular Chemistry of $\begin{array}{lllllll}\text { Fullerenes. Chem. Soc. Rev. 2007, } 36 & \text { (2), 189-197. }\end{array}$ https://doi.org/10.1039/B614883M.

(45) Stefankiewicz, A. R.; Tamanini, E.; Pantoş, G. D.; Sanders, J. K. M. Proton-Driven Switching Between Receptors for C60 and C70. Angew. Chem. Int. Ed. 2011, 50 (25), 5725-5728. https://doi.org/10.1002/anie.201100806.

(46) Gil-Ramírez, G.; Karlen, S. D.; Shundo, A.; Porfyrakis, K.; Ito, Y.; Briggs, G. A. D.; Morton, J. J. L.; Anderson, H. L. A Cyclic Porphyrin Trimer as a Receptor for Fullerenes. Org. Lett. 2010, 12 (15), 3544-3547. https://doi.org/10.1021/ol101393h.

(47) Moreira, L.; Calbo, J.; Illescas, B. M.; Aragó, J.; Nierengarten, I.; Delavaux-Nicot, B.; Ortí, E.; Martín, N.; Nierengarten, J.-F. Metal-Atom Impact on the Self-Assembly of 
Cup-and-Ball Metalloporphyrin-Fullerene Conjugates. Angew. Chem. Int. Ed. 2015, 54 (4), 1255-1260. https://doi.org/10.1002/anie.201409487.

(48) Ogoshi, T.; Ueshima, N.; Sakakibara, F.; Yamagishi, T.; Haino, T. Conversion from Pillar[5]Arene to Pillar[6-15]Arenes by Ring Expansion and Encapsulation of C60 by Pillar[n]Arenes with Nanosize Cavities. Org. Lett. 2014, 16 (11), 2896-2899. https://doi.org/10.1021/ol501039u.

(49) Yokoi, H.; Hiraoka, Y.; Hiroto, S.; Sakamaki, D.; Seki, S.; Shinokubo, H. NitrogenEmbedded Buckybowl and Its Assembly with $\mathrm{C}_{60}$. Nat. Commun. 2015, 6, 8215. https://doi.org/10.1038/ncomms9215.

(50) Sun, W.; Wang, Y.; Ma, L.; Zheng, L.; Fang, W.; Chen, X.; Jiang, H. Self-Assembled Carcerand-like Cage with a Thermoregulated Selective Binding Preference for Purification of High-Purity $\mathrm{C} 60$ and C70. J. Org. Chem. 2018. https://doi.org/10.1021/acs.joc.8b02674.

(51) Preferable to Aggregates of Fullerenes Which Can Change Their Optoelectronic Properties.

(52) Canevet, D.; Pérez, E. M.; Martín, N. Wraparound Hosts for Fullerenes: Tailored Macrocycles and Cages. Angew. Chem. Int. Ed. 2011, 50 (40), 9248-9259. https://doi.org/10.1002/anie.201101297.

(53) García-Simón, C.; Costas, M.; Ribas, X. Metallosupramolecular Receptors for Fullerene Binding and Release. Chem. Soc. Rev. 2015, 45 (1), 40-62. https://doi.org/10.1039/C5CS00315F.

(54) Yokoi, H.; Hiroto, S.; Sakamaki, D.; Seki, S.; Shinokubo, H. Supramolecular Assemblies of a Nitrogen-Embedded Buckybowl Dimer with C60. Chem. Sci. 2018, 9 (4), 819-824. https://doi.org/10.1039/C7SC04453D.

(55) Rosokha, S. V.; Kochi, J. K. Continuum of Outer- and Inner-Sphere Mechanisms for Organic Electron Transfer. Steric Modulation of the Precursor Complex in Paramagnetic (Ion-Radical) Self-Exchanges. J. Am. Chem. Soc. 2007, 129 (12), 36833697. https://doi.org/10.1021/ja069149m.

(56) Rosokha, S. V.; Kochi, J. K. Fresh Look at Electron-Transfer Mechanisms via the Donor/Acceptor Bindings in the Critical Encounter Complex. Acc. Chem. Res. 2008, 41 (5), 641-653. https://doi.org/10.1021/ar700256a.

(57) Guha, S.; Goodson, F. S.; Corson, L. J.; Saha, S. Boundaries of Anion/Naphthalenediimide Interactions: From Anion- $\pi$ Interactions to Anion-Induced Charge-Transfer and Electron-Transfer Phenomena. J. Am. Chem. Soc. 2012, 134 (33), 13679-13691. https://doi.org/10.1021/ja303173n.

(58) Würthner, F.; Saha-Möller, C. R.; Fimmel, B.; Ogi, S.; Leowanawat, P.; Schmidt, D. Perylene Bisimide Dye Assemblies as Archetype Functional Supramolecular Materials. Chem. Rev. 2016, $116 \quad$ (3), 962-1052. https://doi.org/10.1021/acs.chemrev.5b00188.

(59) Würthner, F. Perylene Bisimide Dyes as Versatile Building Blocks for Functional Supramolecular Architectures. Chem. Commun. 2004, No. 14, 1564-1579. https://doi.org/10.1039/B401630K.

(60) Spenst, P.; Würthner, F. Photo- and Redoxfunctional Cyclophanes, Macrocycles, and Catenanes Based on Aromatic Bisimides. J. Photochem. Photobiol. C Photochem. Rev. 2017, 31, 114-138. https://doi.org/10.1016/j.jphotochemrev.2017.03.002.

(61) Barendt, T. A.; Ferreira, L.; Marques, I.; Félix, V.; Beer, P. D. Anion- and SolventInduced Rotary Dynamics and Sensing in a Perylene Diimide [3]Catenane. J. Am. Chem. Soc. 2017. https://doi.org/10.1021/jacs.7b04295. 
(62) Huang, C.; Barlow, S.; Marder, S. R. Perylene-3,4,9,10-Tetracarboxylic Acid Diimides: Synthesis, Physical Properties, and Use in Organic Electronics. J. Org. Chem. 2011, 76 (8), 2386-2407. https://doi.org/10.1021/jo2001963.

(63) Schwartz, P.-O.; Biniek, L.; Zaborova, E.; Heinrich, B.; Brinkmann, M.; Leclerc, N.; Méry, S. Perylenediimide-Based Donor-Acceptor Dyads and Triads: Impact of Molecular Architecture on Self-Assembling Properties. J. Am. Chem. Soc. 2014, 136 (16), 5981-5992. https://doi.org/10.1021/ja4129108.

(64) Dössel, L. F.; Kamm, V.; Howard, I. A.; Laquai, F.; Pisula, W.; Feng, X.; Li, C.; Takase, M.; Kudernac, T.; De Feyter, S.; et al. Synthesis and Controlled SelfAssembly of Covalently Linked Hexa-Peri-Hexabenzocoronene/Perylene Diimide Dyads as Models To Study Fundamental Energy and Electron Transfer Processes. $J$. Am. Chem. Soc. 2012, 134 (13), 5876-5886. https://doi.org/10.1021/ja211504a.

(65) Lee, K. J.; Woo, J. H.; Kim, E.; Xiao, Y.; Su, X.; Mazur, L. M.; Attias, A.-J.; Fages, F.; Cregut, O.; Barsella, A.; et al. Electronic Energy and Electron Transfer Processes in Photoexcited Donor-Acceptor Dyad and Triad Molecular Systems Based on Triphenylene and Perylene Diimide Units. Phys. Chem. Chem. Phys. 2016, 18 (11), 7875-7887. https://doi.org/10.1039/C5CP06279A.

(66) Chamberlain, T. W.; Davies, E. S.; Khlobystov, A. N.; Champness, N. R. MultiElectron-Acceptor Dyad and Triad Systems Based on Perylene Bisimides and Fullerenes. Chem. - Eur. J. 2011, 17 (13), 3759-3767. https://doi.org/10.1002/chem.201003092.

(67) Baffreau, J.; Leroy-Lhez, S.; Vân Anh, N.; Williams, R. M.; Hudhomme, P. Fullerene C60-Perylene-3,4:9,10-Bis(Dicarboximide) Light-Harvesting Dyads: Spacer-Length and Bay-Substituent Effects on Intramolecular Singlet and Triplet Energy Transfer. Chem. - Eur. J. 2008, 14 (16), 4974-4992. https://doi.org/10.1002/chem.200800156.

(68) Gómez, R.; Segura, J. L.; Martín, N. Highly Efficient Light-Harvesting Organofullerenes. Org. Lett. 2005, 7 (4), 717-720. https://doi.org/10.1021/ol047451z.

(69) Hua, J.; Meng, F.; Ding, F.; Li, F.; Tian, H. Novel Soluble and Thermally-Stable Fullerene Dyad Containing Perylene. J. Mater. Chem. 2004, 14 (12), 1849-1853. https://doi.org/10.1039/B316996K.

(70) Xiao, S.; Li, Y.; Li, Y.; Zhuang, J.; Wang, N.; Liu, H.; Ning, B.; Liu, Y.; Lu, F.; Fan, L.; et al. [60]Fullerene-Based Molecular Triads with Expanded Absorptions in the Visible Region: Synthesis and Photovoltaic Properties. J. Phys. Chem. B 2004, 108 (43), 16677-16685. https://doi.org/10.1021/jp0478413.

(71) Wang, N.; Li, Y.; He, X.; Gan, H.; Li, Y.; Huang, C.; Xu, X.; Xiao, J.; Wang, S.; Liu, $\mathrm{H}$; et al. Synthesis and Characterization of a Novel Electrical and Optical-Active Triads Containing Fullerene and Perylenebisimide Units. Tetrahedron 2006, 62 (6), 1216-1222. https://doi.org/10.1016/j.tet.2005.10.061.

(72) Baffreau, J.; Perrin, L.; Leroy-Lhez, S.; Hudhomme, P. Perylene-3,4:9,10Bis(Dicarboximide) Linked to [60]Fullerene as a Light-Harvesting Antenna. Tetrahedron Lett. $\mathbf{2 0 0 5 ,} 46 \quad$ (27), 4599-4603. https://doi.org/10.1016/j.tetlet.2005.04.132.

(73) Hua, J.; Meng, F.; Ding, F.; Tian, H. Novel Soluble and Thermally Stable Perylene Dye with Two [60] Fullerene Units. Chem. Lett. 2004, 33 (4), 432-433. https://doi.org/10.1246/c1.2004.432.

(74) Liu, Y.; Wang, N.; Li, Y.; Liu, H.; Li, Y.; Xiao, J.; Xu, X.; Huang, C.; Cui, S.; Zhu, D. A New Class of Conjugated Polyacetylenes Having Perylene Bisimide Units and Pendant Fullerene or Porphyrin Groups. Macromolecules 2005, 38 (11), 4880-4887. https://doi.org/10.1021/ma050434k. 
(75) Li, Y.; Li, Y.; Liu, H.; Wang, S.; Wang, N.; Zhuang, J.; Li, X.; He, X.; Daoben Zhu. Self-Assembled Monolayers of Porphyrin-Perylenetetracarboxylic Diimide-[60] Fullerene on Indium Tin Oxide Electrodes: Enhancement of Light Harvesting in the Visible Light Region. Nanotechnology 2005, $16 \quad$ (9), 1899. https://doi.org/10.1088/0957-4484/16/9/080.

(76) Feng, L.; Rudolf, M.; Wolfrum, S.; Troeger, A.; Slanina, Z.; Akasaka, T.; Nagase, S.; Martín, N.; Ameri, T.; Brabec, C. J.; et al. A Paradigmatic Change: Linking Fullerenes to Electron Acceptors. J. Am. Chem. Soc. 2012, 134 (29), 12190-12197. https://doi.org/10.1021/ja3039695.

(77) Shibano, Y.; Umeyama, T.; Matano, Y.; Tkachenko, N. V .; Lemmetyinen, H.; Imahori, H. Synthesis and Photophysical Properties of Electron-Rich Perylenediimide-Fullerene Dyad. Org. Lett. 2006, 8 (20), 4425-4428. https://doi.org/10.1021/ol061506a.

(78) Martín-Gomis, L.; Rotas, G.; Ohkubo, K.; Fernández-Lázaro, F.; Fukuzumi, S.; Tagmatarchis, N.; Sastre-Santos, Á. Does a Nitrogen Matter? Synthesis and Photoinduced Electron Transfer of Perylenediimide Donors Covalently Linked to C59N and C60 Acceptors. Nanoscale 2015, 7 (16), 7437-7444. https://doi.org/10.1039/C5NR00308C.

(79) Pla, S.; Niemi, M.; Martín-Gomis, L.; Fernández-Lázaro, F.; Lemmetyinen, H.; Tkachenko, N. V.; Sastre-Santos, Á. Charge Separation and Charge Recombination Photophysical Studies in a Series of Perylene-C60 Linear and Cyclic Dyads. Phys. Chem. Chem. Phys. 2016, 18 (5), 3598-3605. https://doi.org/10.1039/C5CP06340J.

(80) Baffreau, J.; Leroy-Lhez, S.; Hudhomme, P.; Groeneveld, M. M.; van Stokkum, I. H. M.; Williams, R. M. Superabsorbing Fullerenes: Spectral and Kinetic Characterization of Photoinduced Interactions in Perylenediimide-Fullerene-C60 Dyads. J. Phys. Chem. A 2006, 110 (49), 13123-13125. https://doi.org/10.1021/jp066415+.

(81) Liu, Y.; Xiao, S.; Li, H.; Li, Y.; Liu, H.; Lu, F.; Zhuang, J.; Zhu, D. Self-Assembly and Characterization of A Novel Hydrogen-Bonded Nanostructure. J. Phys. Chem. B 2004, 108 (20), 6256-6260. https://doi.org/10.1021/jp0373853.

(82) Hofmann, C. C.; Lindner, S. M.; Ruppert, M.; Hirsch, A.; Haque, S. A.; Thelakkat, M.; Köhler, J. Mutual Interplay of Light Harvesting and Triplet Sensitizing in a Perylene Bisimide Antenna-Fullerene Dyad. J. Phys. Chem. B 2010, 114 (28), 9148-9156. https://doi.org/10.1021/jp1035585.

(83) Shibano, Y.; Umeyama, T.; Matano, Y.; Tkachenko, N. V.; Lemmetyinen, H.; Araki, Y.; Ito, O.; Imahori, H. Large Reorganization Energy of Pyrrolidine-Substituted Perylenediimide in Electron Transfer. J. Phys. Chem. C 2007, 111 (16), 6133-6142. https://doi.org/10.1021/jp068893q.

(84) Zhao, Y.; Wasielewski, M. R. 3,4:9,10-Perylenebis(Dicarboximide) Chromophores That Function as Both Electron Donors and Acceptors. Tetrahedron Lett. 1999, 40 (39), 7047-7050. https://doi.org/10.1016/S0040-4039(99)01468-9.

(85) Lukas, A. S.; Zhao, Y.; Miller, S. E.; Wasielewski, M. R. Biomimetic Electron Transfer Using Low Energy Excited States: A Green Perylene-Based Analogue of Chlorophyll A. J. Phys. Chem. B 2002, 106 (6), 1299-1306. https://doi.org/10.1021/jp014073w.

(86) Münich, P. W.; Schierl, C.; Dirian, K.; Volland, M.; Bauroth, S.; Wibmer, L.; Syrgiannis, Z.; Clark, T.; Prato, M.; Guldi, D. M. Tuning the Carbon Nanotube Selectivity: Optimizing Reduction Potentials and Distortion Angles in Perylenediimides. J. Am. Chem. Soc. 2018, 140 (16), 5427-5433. https://doi.org/10.1021/jacs.8b00452. 
(87) Beauvilliers, E. E.; Topka, M. R.; Dinolfo, P. H. Synthesis and Characterization of Perylene Diimide Based Molecular Multilayers Using CuAAC: Towards Panchromatic Assemblies. RSC Adv. 2014, 4 (62), 32866-32875. https://doi.org/10.1039/C4RA04512B.

(88) Hancock, L. M.; Beer, P. D. Sodium and Barium Cation-Templated Synthesis and Cation-Induced Molecular Pirouetting of a Pyridine N-Oxide Containing [2]Rotaxane. Chem. Commun. 2011, 47 (21), 6012-6014. https://doi.org/10.1039/C1CC11224D.

(89) Saito, Y.; Matsumoto, K.; Bag, S. S.; Ogasawara, S.; Fujimoto, K.; Hanawa, K.; Saito, I. C8-Alkynyl- and Alkylamino Substituted 2'-Deoxyguanosines: A Universal Linker for Nucleic Acids Modification. Tetrahedron 2008, 64 (16), 3578-3588. https://doi.org/10.1016/j.tet.2008.01.091.

(90) Shibano, Y.; Umeyama, T.; Matano, Y.; Imahori, H. Electron-Donating Perylene Tetracarboxylic Acids for Dye-Sensitized Solar Cells. Org. Lett. 2007, 9 (10), 19711974. https://doi.org/10.1021/ol070556s.

(91) Seibt, J.; Marquetand, P.; Engel, V.; Chen, Z.; Dehm, V.; Würthner, F. On the Geometry Dependence of Molecular Dimer Spectra with an Application to Aggregates of Perylene Bisimide. Chem. Phys. 2006, 328 (1-3), 354-362. https://doi.org/10.1016/j.chemphys.2006.07.023.

(92) For Aabs,Max; AO-O/AO-1 = 2 Indicating the Absence of Intermolecular or Intramolecular Aromatic Stacking between PDIs in Solution.

(93) Ruoff, R. S.; Tse, D. S.; Malhotra, R.; Lorents, D. C. Solubility of Fullerene (C60) in a Variety of Solvents. J. Phys. Chem. 1993, 97 (13), 3379-3383. https://doi.org/10.1021/j100115a049.

(94) So That Changes Could Be Observed throughout the Spectral Window, the Electronic Spectra Were Corrected for Absorbances from Fullerenes at $\lambda<600 \mathrm{Nm}$.

(95) Calculated by Integration of Peak Intensities from $1 \mathrm{em}=700$ to $850 \mathrm{Nm}$.

(96) Iwamoto, T.; Slanina, Z.; Mizorogi, N.; Guo, J.; Akasaka, T.; Nagase, S.; Takaya, H.; Yasuda, N.; Kato, T.; Yamago, S. Partial Charge Transfer in the Shortest Possible Metallofullerene Peapod, La@C82ᄃ[11]Cycloparaphenylene. Chem. - Eur. J. 2014, 20 (44), 14403-14409. https://doi.org/10.1002/chem.201403879.

(97) Http://Supramolecular.Org.

(98) This Region Was Also Chosen Because the Absence of Spectral Overlap with Fullerene Bands Permitted the Use of Non-Corrected Absorption Spectra Thus Minimizing Error. Non-Sigmoidal Residues and Low Fitting Covariances Indicate an Appropriate Binding Model.

(99) Tashiro, K.; Aida, T.; Zheng, J.-Y.; Kinbara, K.; Saigo, K.; Sakamoto, S.; Yamaguchi, K. A Cyclic Dimer of Metalloporphyrin Forms a Highly Stable Inclusion Complex with C60. J. Am. Chem. Soc. 1999, 121 (40), 9477-9478. https://doi.org/10.1021/ja992416m.

(100) Perturbations Were Too Small to Be Accurately Fitted.

(101) Diao, G.; Li, L.; Zhang, Z. The Electrochemical Reduction of Fullerenes, C60 and C70. Talanta 1996, 43 (10), 1633-1637. https://doi.org/10.1016/0039-9140(96)018796.

(102) C60 Is Nearly Ten Times More Soluble in O-DCB than Toluene.

(103) Tsuchiya, T.; Wielopolski, M.; Sakuma, N.; Mizorogi, N.; Akasaka, T.; Kato, T.; Guldi, D. M.; Nagase, S. Stable Radical Anions Inside Fullerene Cages: Formation of Reversible Electron Transfer Systems. J. Am. Chem. Soc. 2011, 133 (34), 1328013283. https://doi.org/10.1021/ja205391v.

(104) Indicative of a Strong Electronic Component to the Host-Guest Interaction with C70. 
(105) A Higher Concentration of C60 Guest Was Required to Achieve Similar $\Delta \delta$ in This More Competitive Solvent.

(106) Saegusa, Y.; Ishizuka, T.; Kojima, T.; Mori, S.; Kawano, M.; Kojima, T. Supramolecular Interaction of Fullerenes with a Curved $\pi$-Surface of a Monomeric Quadruply Ring-Fused Porphyrin. Chem. - Eur. J. 2015, 21 (14), 5302-5306. https://doi.org/10.1002/chem.201500389.

(107) Gallego, M.; Calbo, J.; Krick Calderon, R. M.; Pla, P.; Hsieh, Y.-C.; Pérez, E. M.; Wu, Y.-T.; Ortí, E.; Guldi, D. M.; Martín, N. Complexation and Electronic Communication between Corannulene-Based Buckybowls and a Curved Truxene-TTF Donor. Chem. Eur.J. 2017, 23 (15), 3666-3673. https://doi.org/10.1002/chem.201604921.

(108) The Twisted PDI Framework Appears to Allow Some of the Aromatic Protons to Be Directed towards the Fullerene Cage.

(109) Hung, R. R.; Grabowski, J. J. A Precise Determination of the Triplet Energy of Carbon (C60) by Photoacoustic Calorimetry. J. Phys. Chem. 1991, 95 (16), 6073-6075. https://doi.org/10.1021/j100169a007.

(110) Kandrashkin, Y. E.; van der Est, A. Time-Resolved EPR Spectroscopy of Photosynthetic Reaction Centers: From Theory to Experiment. Appl. Magn. Reson. 2007, 31 (1), 105-122. https://doi.org/10.1007/BF03166250.

(111) By Comparison to the Electronic Absorption Spectrum of an Electrochemically (J. Phys. Chem. B 2002, 106, 1299) and Photochemically (Org Lett 2006 4425) Generated $[P D I] \cdot+$.

(112) Giaimo, J. M.; Gusev, A. V.; Wasielewski, M. R. Excited-State Symmetry Breaking in Cofacial and Linear Dimers of a Green Perylenediimide Chlorophyll Analogue Leading to Ultrafast Charge Separation. J. Am. Chem. Soc. 2002, 124 (29), 8530-8531. https://doi.org/10.1021/ja0264221.

(113) van der Boom, T.; Hayes, R. T.; Zhao, Y.; Bushard, P. J.; Weiss, E. A.; Wasielewski, M. R. Charge Transport in Photofunctional Nanoparticles Self-Assembled from Zinc 5,10,15,20-Tetrakis(Perylenediimide)Porphyrin Building Blocks. J. Am. Chem. Soc. 2002, 124 (32), 9582-9590. https://doi.org/10.1021/ja026286k.

(114) Ito, O. Photoinduced Electron Transfer of Fullerenes (C60 and C70) Studied by Transient Absorption Measurements in near-IR Region. Res. Chem. Intermed. 1997, 23 (5), 389-402. https://doi.org/10.1163/156856797X00141.

(115) Cataldo, F.; Iglesias-Groth, S.; Manchado, A. On the Radical Anion Spectra of Fullerenes C60 and C70. Fuller. Nanotub. Carbon Nanostructures 2013, 21 (6), 537548. https://doi.org/10.1080/1536383X.2011.643422.

(116) Isobe, H.; Tanaka, T.; Nakanishi, W.; Lemiègre, L.; Nakamura, E. Regioselective Oxygenative Tetraamination of [60]Fullerene. Fullerene-Mediated Reduction of Molecular Oxygen by Amine via Ground State Single Electron Transfer in Dimethyl Sulfoxide. J. Org. Chem. 2005, 70 (12), 4826-4832. https://doi.org/10.1021/jo050432y.

(117) Eaton, S. S.; Eaton, G. R. EPR Spectra of C60 Anions. Appl. Magn. Reson. 1996, 11 (2), 155-170. https://doi.org/10.1007/BF03162051.

(118) Greaney, M. A.; Gorun, S. M. Production, Spectroscopy and Electronic Structure of Soluble Fullerene Ions. J. Phys. Chem. 1991, 95 (19), 7142-7144. https://doi.org/10.1021/j100172a012.

(119) Douthwaite, R. E.; Brough, A. R.; Green, M. L. H. Synthesis and Characterisation of NaC60.5thf. J. Chem. Soc. Chem. Commun. 1994, 0 (3), 267-268. https://doi.org/10.1039/C39940000267. 
(120) Krusic, P. J.; Wasserman, E.; Parkinson, B. A.; Malone, B.; Holler, E. R.; Keizer, P. N.; Morton, J. R.; Preston, K. F. Electron Spin Resonance Study of the Radical Reactivity of C60. J. Am. Chem. Soc. 1991, 113 (16), 6274-6275. https://doi.org/10.1021/ja00016a056.

(121) Under the Conditions Used It Was Not Possible to Resolve the Signal for the PDI Radical Cation. Presumably, the Signal Has a Narrower Line Width than That of the C60 Radical Anion and so Cannot Be Observed.

(122) Tsuchiya, T.; Sato, K.; Kurihara, H.; Wakahara, T.; Maeda, Y.; Akasaka, T.; Ohkubo, K.; Fukuzumi, S.; Kato, T.; Nagase, S. Spin-Site Exchange System Constructed from Endohedral Metallofullerenes and Organic Donors. J. Am. Chem. Soc. 2006, 128 (45), 14418-14419. https://doi.org/10.1021/ja062634x.

(123) Park, J. S.; Karnas, E.; Ohkubo, K.; Chen, P.; Kadish, K. M.; Fukuzumi, S.; Bielawski, C. W.; Hudnall, T. W.; Lynch, V. M.; Sessler, J. L. Ion-Mediated Electron Transfer in a Supramolecular Donor-Acceptor Ensemble. Science 2010, 329 (5997), 1324-1327. https://doi.org/10.1126/science.1192044.

(124) There Is a Documented Affinity for EMFs with Solvents Such as Pyridine and DMF Due to an Interaction with the Basic N Atom.

(125) Tsuchiya, T.; Sato, K.; Kurihara, H.; Wakahara, T.; Nakahodo, T.; Maeda, Y.; Akasaka, T.; Ohkubo, K.; Fukuzumi, S.; Kato, T.; et al. Host-Guest Complexation of Endohedral Metallofullerene with Azacrown Ether and Its Application. J. Am. Chem. Soc. 2006, 128 (20), 6699-6703. https://doi.org/10.1021/ja0608390.

(126) Pérez, E. M.; Sánchez, L.; Fernández, G.; Martín, N. ExTTF as a Building Block for Fullerene Receptors. Unexpected Solvent-Dependent Positive Homotropic Cooperativity. J. Am. Chem. Soc. 2006, 128 (22), 7172-7173. https://doi.org/10.1021/ja0621389.

(127) Nielsen, K. A.; Cho, W.-S.; Sarova, G. H.; Petersen, B. M.; Bond, A. D.; Becher, J.; Jensen, F.; Guldi, D. M.; Sessler, J. L.; Jeppesen, J. O. Supramolecular Receptor Design: Anion-Triggered Binding of C60. Angew. Chem. Int. Ed. 2006, 45 (41), 68486853. https://doi.org/10.1002/anie.200602724.

(128) Boyd, P. D. W .; Reed, C. A. Fullerene-Porphyrin Constructs. Acc. Chem. Res. 2005, 38 (4), 235-242. https://doi.org/10.1021/ar040168f.

(129) Rehm, D.; Weller, A. Kinetics of Fluorescence Quenching by Electron and H-Atom Transfer. Isr. J. Chem. 1970, 8 (2), 259-271. https://doi.org/10.1002/ijch.197000029.

(130) Tsuchiya, T.; Kurihara, H.; Sato, K.; Wakahara, T.; Akasaka, T.; Shimizu, T.; Kamigata, N.; Mizorogi, N.; Nagase, S. Supramolecular Complexes of La@C82 with Unsaturated Thiacrown Ethers. Chem. Commun. 2006, 0 (34), 3585-3587. https://doi.org/10.1039/B606183D.

(131) Electron Transfer May Also Be Assisted by Some Aggregation of Fullerenes in Nitrobenzene, a Process Which Has Been Shown to Lower Their Reduction Potential.

(132) In Agreement with Our Findings, Only When $\Delta G e t \leq 24$ Kcal Mol-1 Was Electron Transfer to Fullerene Observed Experimentally. (Chem Comm 2006 3585).

(133) Schilder, A.; Gotschy, B.; Seidl, A.; Gompper, R. Preparation and Characterisation of the C60 Charge Transfer Complex C60-.[1,1',3,3'-Tetramethyl- $\Delta 2,2^{\prime}$ Bi(Imidazolidine)]+. Chem. Phys. 1995, $193 \quad$ (3), 321-326. https://doi.org/10.1016/0301-0104(95)00013-E.

(134) Klos, H.; Rystau, I.; Schütz, W.; Gotschy, B.; Skiebe, A.; Hirsch, A. Doping of C60 with Tertiary Amines: TDAE, DBU, DBN. A Comparative Study. Chem. Phys. Lett. 1994, 224 (3), 333-337. https://doi.org/10.1016/0009-2614(94)00550-8. 
(135) By Contrast Some of the Longest Reported Lifetimes of Photoinduced Charge Separated States in Fullerene Dyads Are in the Ms Regime (Add Ref Pg 192 in Fullerene Book).

(136) Konishi, T.; Ikeda, A.; Kishida, T.; Rasmussen, B. S.; Fujitsuka, M.; Ito, O.; Shinkai, S. Photoinduced Electron Transfer between C60-Pendant Calixarene and Captured Electron Donor: Improvement of Electron-Transfer Efficiency by Applying Host-Guest Chemistry. J. Phys. Chem. A 2002, 106 (43), 10254-10260. https://doi.org/10.1021/jp021305y.

(137) Perturbations of $1 H$ NMR and Vis-NIR Spectra (Figures SX,X) Analogous to Those Recorded in Toluene Indicated Residual Ground State Charge Transfer Interactions in Solution (i.e. the Polarised Complex [4] $+\subset[C 60] \Delta-$ ).

(138) With a Caveat That If the Steric Hindrance of the Donor Is Too Large It Reduced the Efficiency of SET to C60 (JACS 2011 13280), Meaning That Green Box Appears to Sit between These Two Extremes.

(139) Iwamoto, T.; Watanabe, Y.; Takaya, H.; Haino, T.; Yasuda, N.; Yamago, S. Size- and Orientation-Selective Encapsulation of C70 by Cycloparaphenylenes. Chem. - Eur. J. 2013, 19 (42), 14061-14068. https://doi.org/10.1002/chem.201302694.

(140) Pérez, E. M.; Martín, N. Molecular Tweezers for Fullerenes. Pure Appl. Chem. 2010, 82 (3), 523-533. https://doi.org/10.1351/PAC-CON-09-09-27.

(141) Isla, H.; Gallego, M.; Pérez, E. M.; Viruela, R.; Ortí, E.; Martín, N. A Bis-ExTTF Macrocyclic Receptor That Associates C60 with Micromolar Affinity. J. Am. Chem. Soc. 2010, 132 (6), 1772-1773. https://doi.org/10.1021/ja910107m.

(142) Utschig, L. M.; Thurnauer, M. C. Metal Ion Modulated Electron Transfer in Photosynthetic Proteins. Acc. Chem. Res. 2004, 37 (7), 439-447. https://doi.org/10.1021/ar020197v.

(143) Fukuzumi, S. Roles of Metal Ions in Controlling Bioinspired Electron-Transfer Systems. Metal Ion-Coupled Electron Transfer. In Progress in Inorganic Chemistry; Wiley-Blackwell, 2009; pp 49-154. https://doi.org/10.1002/9780470440124.ch2.

(144) Ferreira, K. N.; Iverson, T. M.; Maghlaoui, K.; Barber, J.; Iwata, S. Architecture of the Photosynthetic Oxygen-Evolving Center. Science 2004, 303 (5665), 1831-1838. https://doi.org/10.1126/science.1093087. 
Authors are required to submit a graphic entry for the Table of Contents (TOC) that, in conjunction with the manuscript title, should give the reader a representative idea of one of the following: A key structure, reaction, equation, concept, or theorem, etc., that is discussed in the manuscript. Consult the journal's Instructions for Authors for TOC graphic specifications.

Insert Table of Contents artwork here

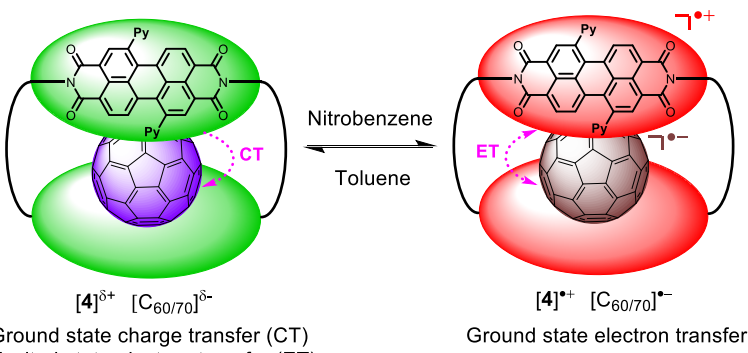

Excited state electron transfer (ET)

Ground state electron transfer 